\title{
Desenvolvimento larval de Chasmagnathus granulata Dana (Crustacea, Decapoda, Grapsidae), em laboratório. I. Estudo da morfologia de cerdas nas fases de zoea e megalopa e das variações dos padrões corporais da fase de megalopa
}

\author{
Paulo Juarez Rieger ${ }^{1}$ \\ Ana Lucia F. Santos ${ }^{2}$
}

\begin{abstract}
Larval development of Chasmagnathus granulata Dana (Crustacea, Decapoda, Grapsidae) under laboratory conditions. I. Study of setae morphology in the zoea and megalopae phases and the variations in body patterns of megalopae. The study of Chasmagnathus granulata Dana 1851 was done with the setae morphology point of view. The main objective of this description was to find differents kinds of morphologicals types of setae. During this work anomalous structures were found in megalopal phase, such as: many kinds of rostral and lateral spines, as well as many kinds of spines on the telson and one kind of dorsal spine which never was cited before in the literature concerning to this specie.
\end{abstract}

KEY WORDS. Crustacea, Decapoda, Grapsidae, larval development, murphology

Das espécies da família Grapsidae encontradas na região da cidade do Rio Grande, a mais abundante é Chasmagnathus granulata Dana, 1851, que vive sob pedras à margem da água ou construindo galerias, constituindo os típicos caranguejais. Esta espécie teve o estudo de seu desenvolvimento larval realizado por BOSCHI et al. (1967). Poucos estudos foram realizados sobre morfologia de cerdas em Crustacea sendo que os primeiros trabalhos datam do século XIX (CARBONNIER 1869; HUXLEY 1880).

Já no início do século XX, surgiram os trabalhos de PANNING (1924), RINGEL (1924), FERRIS (1934) que ainda não foram precisos quanto à definição da diferença entre cerdas e espinhos.

Com as recentes pesquisas sobre morfologia de cerdas iniciados por THOMAS (1970), Fish (1972), FARMER (1974), VAN HERP \& BELLON-HUMBERT (1978), POHLE \& TELFORD (1981), LONGMUIR (1983), JACQUES (1989), WATLING (1989), INGLE (1992) e CALAZANS \& INGLE (1998), utilizando microscopia óptica e eletrônica, tornou-se possível realizar um estudo mais detalhado sobre tais estruturas. No que se refere à importância das cerdas sob o ponto de vista da morfologia funcional, como por exemplo nas peças bucais, nos processos de captura, seleção, manipulação do alimento, nas diversas fases do desenvolvimento pós-embrionário,

1) Laboratório Zoologia de Crustáceos Decápodos, Fundação Universidade do Rio Grande. Avenida Itália, Km 08, 96201-900 Rio Grande, Rio Grande do Sul, Brasil.

E-mail: dmbpjr@super.furg.br

2) Bolsista de Iniciação Científica FAPERGS. E-mail: ciealfs@super.furg.br 
os trabalhos de FACTOR (1978) e LAVALLI \& FACTOR (1992, 1995), apresentam contribuições científicas relevantes para uma melhor compreensão sobre a morfologia das cerdas.

Com relação a fase de megalopa de C. granulata foram encontradas variações nos padrões corporais, as quais até o presente, não haviam sido descritas, nem citadas na literatura.

Este trabalho tem por objetivos principais: 1) realizar um estudo sob o ponto de vista morfológico e topográfico das cerdas, em todos os estágios larvais de $C$. granulata; 2) diagnosticar e estabelecer os principais caracteres morfológicos que permitam a identificação, bem como realizar estudo comparativo com o apresentado por BosCHI et al. (1967) para esta espécie; 3) estudo dos diferentes padrões morfológicos corporais na fase de megalopa encontradas no presente cultivo.

\section{MATERIAL E MÉTODOS}

Fêmeas ovígeras foram coletadas manualmente na "Prainha", localizada na região dos Molhes da Barra da cidade de Rio Grande, litoral sul do Estado do Rio Grande do Sul, Brasil.

Após as coletas, os animais foram colocados em caixas térmicas, transportados para o laboratório e mantidos isolados em aquários com aproximadamente 10 litros de água do mar, na salinidade $30 \%$, continuamente aerada.

Os aquários foram colocados em uma sala climatizada com temperatura de $25 \pm 1^{\circ} \mathrm{C}$, sob fotoperiodismo natural e as fêmeas ovígeras observadas várias vezes ao dia, até a constatação da eclosão das larvas e possível ocorrência do estágio de pré-zoea. Foram realizados dois cultivos denominados "A" (com larvas isoladas) e "B" (maciço). Após a eclosão, 100 larvas (zoeas I), oriundas de uma fêmea ovígera, foram atraídas por um foco de luz, removidas do aquário com o auxílio de uma pipeta Pasteur e transferidas, isoladamente, para 100 recipientes plásticos transparentes, com capacidade de $20 \mathrm{ml}$, providos de água do mar previamente filtrada e aerada, sob as mesmas condições de temperatura e salinidade em que eclodiram, sendo diariamente observadas para a constatação da mortalidade e verificação da ocorrência de exúvias, com a consequente determinação das mudanças de estágio. A seguir realizou-se a troca de água dos recipientes e introdução do alimento, o qual consistiu de rotíferos (Brachionus plicatilis, Müller, 1786) e algas (Tetraselmis Stein, 1878), obtidos em laboratório. A partir do segundo estágio de zoea foram adicionados, aproximadamente, 30 nauplius recém eclodidos de Artemia sp. para cada larva, durante todo o desenvolvimento. O cultivo "B", oriundo de outra fêmea ovígera, foi realizado em 100 recipientes plásticos transparentes, com capacidade de $50 \mathrm{ml}$, contendo aproximadamente 20 larvas por recipiente, perfazendo um total aproximado de 2000 larvas, destinado exclusivamente para a obtenção de um maior número de jovens que, somado aos do cultivo "A", garantiriam um maior número de exemplares para os estudos da fase juvenil.

Para o cultivo "B" não houve a mesma periodicidade diária de observação do cultivo "A", sendo a troca de água e alimentação, realizadas a cada 2(3) dias. 
As larvas e os jovens mortos, bem como as exúvias de cada estágio, foram fixadas e preservadas em uma mistura de álcool etílico $96 \%$ e glicerina, na proporção de $1: 1$.

Os desenhos, medidas e as descrições morfológicas das zoeas e megalopas, bem como de todos os seus apêndices, foram efetuados com o auxílio de um microscópio óptico Olympus BX-40, equipado com câmara clara e ocular micrométrica, a partir de exúvias e animais conservados. Para cada estágio do desenvolvimento larval, estes estudos foram realizados em cerca de 10 indivíduos.

Os desenhos dos apêndices, bem como das cerdas foram realizados de maneira estilizada. A medida do comprimento da carapaça das megalopas foi obtida entre o início da região frontal e o término da região intestinal; a largura da carapaça foi obtida na região mediana da mesma, que corresponde à de maior largura. As medidas do comprimento dos espinhos dorsal, rostral e lateral foram obtidas à partir da região mediana da base até a extremidade distal dos mesmos.

$\mathrm{Na}$ apresentação das descrições morfológicas e tabelas, os números entre parênteses significam valores alternativos, de menor ocorrência na estrutura mencionada.

A representação gráfica das peças foi efetuada utilizando-se um índice de resolução de 400 vezes. Foram considerados como elementos fundamentais para determinação dos tipos de cerdas o "socket", a haste, lúmen, cerdulas e porção terminal da haste.

A confecção das lâminas consistiu na preparação das exúvias por técnica de coloração histológica com o auxílio do corante tricrômico de Mallory através das seguintes etapas: 1) com o auxílio de uma pipeta Pasteur remover as exúvias fixadas para uma peneira de 300 micra; 2) hidratar 10 minutos em cada álcool $\left(96^{\circ}, 50^{\circ}\right.$, $\left.30^{\circ}, 10^{\circ}\right) ; 3$ ) corar 45 minutos no corante "A" (Fucsina); 4) lavar com água destilada; 5) deixar 60 minutos no corante "B" (Azul de anilina e Orange G); 6) lavar duas vezes com água destilada; 7$)$ desidratar 10 minutos em cada álcool $\left(10^{\circ}, 30^{\circ}, 50^{\circ}\right.$, $\left.96^{\circ}\right) ; 8$ ) montar a lâmina semi permanente com álcool glicerinado (3 partes de álcool $96^{\circ}$ e sete partes de glicerina) e lamínula; 9) selar com esmalte incolor.

A cultura das larvas em laboratório foi realizada em linhas gerais, segundo as metodologias indicadas por FrANSOZO \& HEBLING (1986), FRANSOZO (1987), Rodrigues \& HEBLING (1989), BRossi-GARCIA \& Rodrigues (1993), RIEGER \& HEBLING (1993).

A terminologia adotada baseia-se nas utilizadas por COSTLOW \& BOOKHOUT (1959), WeAR (1967), THOMAS (1970), ChristiANSEN (1973), NARCHI (1973), Rodrigues (1976), Pohle \& Telford (1981), Hebling \& Fransozo (1982), WATLING (1989), INGLE (1992), BROSSI-GARCIA \& RODRIGUES (1993).

A determinação dos tipos de cerdas na fase larval foi realizada utilizando-se os conceitos propostos por POHLE \& TELFORD (1981) por se mostrarem mais adequados aos estudos, uma vez que tais autores os apresentam baseados em microscopia óptica.

Para a determinação dos tipos de cerdas foram utilizados os seguintes conceitos: 
Cerda simples: desprovida de projeções cuticulares

Cerda plumosa: com cérdulas que se dispõem da base até o ápice com pontos de inserção localizados sequencialmente, no mesmo nível de crescimento em torno da haste. Cerdas paposas com distribuição das cérdulas ao longo da haste, mas com pontos de inserção dispostos aleatoriamente em relação aos níveis de crescimento em torno da haste.

Cerda cuspidada: com projeções cuticulares em forma de dentículos, na extremidade distal da cerda.

$\mathrm{Na}$ apresentação dos resultados, figuras e tabelas foram adotados os seguintes símbolos para os diferentes estágios: (ZI-ZIV) primeiro ao quarto estágios da fase de zoea; (MI) estágio único de megalopa; (MII) padrões anômalos de megalopa. Foram consideradas como megalopa I (padrão corporal normal) as que apresentaram características comuns às descritas por BoSCHI et al. (1967) e megalopa II (padrão corporal anômalo) as que apresentaram padrões morfológicos diferentes dos encontrados em megalopa I.

Os trabalhos de laboratório foram efetuados no Laboratório "Zoologia de Crustáceos Decápodos”, Departamento de Ciências Morfo-Biológicas da Fundação Universidade do Rio Grande e depositados na coleção científica do Laboratório Zoologia de Crustáceos Decápodos, lote número 595.

\section{RESULTADOS}

Todas as fêmeas ovígeras utilizadas neste trabalho foram coletadas entre os meses de setembro a maio, sendo que nos meses de junho a agosto não foram encontradas. Nas primeiras fases do desenvolvimento embrionário, os ovos apresentam uma coloração geral roxa. Com o gradual consumo do vitelo, os ovos tornam-se cada vez mais claros e transparentes, até atingirem uma coloração geral cinza, nos dias que antecedem a eclosão. A visualização do pigmento escuro do olho da larva, através da membrana envoltória do ovo, constituiu uma das melhores evidências do final do desenvolvimento embrionário e da iminência da eclosão.

\section{Desenvolvimento larval}

Para Chasmagnathus granulata obteve-se o mesmo resultado obtido por BosCHI et al. (1967), com relação ao desenvolvimento larval que é constituído por uma fase de zoea, com quatro estágios e uma fase de megalopa com apenas um.

A desova das fêmeas é total e não foi observado o estágio de pré-zoea.

Os resultados do cultivo "A" encontram-se na tabela I.

No cultivo "B" foram obtidas 105 megalopas, sendo, 102 (97,14\%) com padrões morfológicos diferenciados: quatro tipos de espinho rostral (R1- 13 indivíduos, R2- 19, R3-11 e R4-10); dois tipos de espinhos laterais arranjados de quatro maneiras distintas (L1- 69 indivíduos, L2- 6, L3- 2, L4- 2); um tipo de espinho dorsal (D1 - 13 indivíduos) e cinco tipos de anormalidades do telso (T1 82 indivídúos, T2 cinco, T3 dois, T4 cinco e T5 cinco) (Tabs II-IV Figs 21-22). Este cultivo sofreu uma interrupção involuntária, uma vez que a estufa BOD apresentou problemas ocasionando a morte de todas as megalopas. 
Tabela 1. Chasmagnathus granulata. Duração e sobrevivência dos estágios de zoea e megalopa I, a partir da eclosão. (X) duração média acumulada (em dias), (D e D') duração mínima e máxima, $(n)$ número de indivíduos vivos, (†) número de indivíduos mortos, $\mathrm{S} \%$ porcentagem de sobrevivência, $n=100$.

\begin{tabular}{lrrrrr}
\hline Parâmetros & Zoeal & Zoea II & Zoea III & Zoea IV & Megalopa I \\
\hline X & 4,14 & 10,96 & 16,15 & 21,56 & 29,44 \\
$D$ & 3,00 & 7,00 & 13,00 & 17,00 & 26,00 \\
$D^{\prime}$ & 7,00 & 27,00 & 25,00 & 28,00 & 36,00 \\
$n$ & 94,00 & 85,00 & 80,00 & 79,00 & 70,00 \\
$\dagger$ & 6,00 & 9,00 & 5,00 & 1,00 & 9,00 \\
S\% & 94,00 & 85,00 & 80,00 & 79,00 & 70,00 \\
\hline
\end{tabular}

Tabela II. Chasmagnathus granulata, Freqüência das estruturas observadas na fase de megalopa II.

\begin{tabular}{cc}
\hline Estrutur a & Frequênc ia \\
\hline R1 & 13 \\
R2 & 19 \\
R3 & 11 \\
R4 & 10 \\
L1 & 69 \\
L2 & 6 \\
L3 & 2 \\
L4 & 2 \\
D1 & 13 \\
T1 & 82 \\
T2 & 5 \\
T3 & 2 \\
T4 & 5 \\
T5 & 5 \\
\hline
\end{tabular}

Tabela III. Chasmagnathus granulata. Combinações das estruturas encontradas na fase de megalopa II.

\begin{tabular}{|c|c|c|c|}
\hline Combinação & Freqüência & Combinação & Freqüência \\
\hline L1, T1 & 18 & Continuação da coluna anterior & \\
\hline $\mathrm{Tr}$ & 13 & $\mathrm{R} 1, \mathrm{~L} 1, \mathrm{~T} 2$ & 1 \\
\hline R2, L1, T1 & 10 & T2 & 1 \\
\hline R1, L1, T1 & 6 & R1, L1, T5 & 1 \\
\hline $\mathrm{R} 3, \mathrm{~L} 1, \mathrm{~T} 1$ & 5 & R3, L1, D1, T4 & 1 \\
\hline R4, L1, T1 & 4 & R4, L1, D1, T1 & 1 \\
\hline L1, D1, D1 & 4 & $\mathrm{R} 4, \mathrm{~T} 1$ & 1 \\
\hline L2, T1 & 3 & L1, D1, T1 & 1 \\
\hline R1, L1, D1, T1 & 3 & $R 2, T 6$ & 1 \\
\hline T4 & 2 & $\mathrm{R} 4, \mathrm{~T} 5$ & 1 \\
\hline$R 3, L 1, T 1$ & 2 & R3, L2, T1 & 1 \\
\hline $\mathrm{R} 1, \mathrm{~T} 1$ & 2 & R4, L1, T1 & 1 \\
\hline R2, L1 & 1 & R3, T5 & 1 \\
\hline L2, T4 & 1 & $\mathrm{R} 1, \mathrm{~T} 2$ & 1 \\
\hline R2, L1, D1L, T1 & 1 & R2, L L1, T4 & 1 \\
\hline T5 & 2 & R2, L1, T3 & 2 \\
\hline $\mathrm{R} 4, \mathrm{Li}$ & 1 & $\mathrm{R} 2, \mathrm{~L} 1, \mathrm{~T} 1$ & 1 \\
\hline $\mathrm{R} 4, \mathrm{~T} 2$ & 1 & D1, T1, L3 & 1 \\
\hline $\mathrm{R} 2, \mathrm{~T} 1$ & 1 & $\mathrm{R} 4, \mathrm{~T} 1, \mathrm{~L} 3$ & 1 \\
\hline L2, T2 & 1 & $\mathrm{R} 2, \mathrm{~T} 1, \mathrm{~L} 4$ & 1 \\
\hline L1, T5 & 1 & T1, L4 & 1 \\
\hline
\end{tabular}


Tabela IV. Chasmagnathus granulata. Análise dos dados morfológicos na fase de zoea e megalopa. $(\mathrm{m})$ Valores mínimos, $(\mathrm{x})$ valores médios, $(\mathrm{M})$ valores máximos; (dp) desvio padrão das médias.

\begin{tabular}{|c|c|c|c|c|c|c|c|c|c|c|c|c|c|c|c|c|}
\hline \multirow{2}{*}{ Estágios } & \multicolumn{4}{|c|}{ Carapaça } & \multicolumn{4}{|c|}{ Espinho rostral } & \multicolumn{4}{|c|}{ Espinho dorsal } & \multicolumn{4}{|c|}{ Espinho lateral } \\
\hline & $m$ & $x$ & M & $\mathrm{dp}$ & $\mathrm{m}$ & $\mathrm{x}$ & M & $d p$ & $\mathrm{~m}$ & $x$ & $M$ & $d p$ & $\mathrm{~m}$ & $x$ & $M$ & $d p$ \\
\hline Zoea I & 0,37 & 0,42 & 0,46 & 0,027 & 0,27 & 0,31 & 0,35 & 0,294 & 0,32 & 0,35 & 0,37 & 0,015 & 0,05 & 0,10 & 0.15 & 0,029 \\
\hline Zoea II & 0,45 & 0,51 & 0,65 & 0,053 & 0,40 & 0,43 & 0,46 & 0,022 & 0,42 & 0,45 & 0,48 & 0,015 & 0.08 & 0,12 & 0,22 & 0.038 \\
\hline Zoea III & 0,60 & 0,70 & 0,75 & 0,055 & 0,60 & 0,63 & 0,70 & 0,048 & 0,40 & 0,56 & 0,65 & 0,085 & 0,06 & 0,10 & 0,15 & 0,035 \\
\hline Zoea IV & 0,90 & 0,97 & 1,05 & 0,292 & 0,60 & 0,75 & 0.85 & 0,070 & 0,52 & 0,71 & 0,80 & 0,083 & 0,10 & 0,12 & 0,15 & 0,020 \\
\hline Megalopa I & 0,90 & 1,07 & 1,20 & 0,105 & - & - & - & - & - & - & - & - & - & - & - & - \\
\hline Megalopa II & 0,98 & 1,06 & 1.10 & 0,050 & - & - & - & - & - & - & - & - & 0,05 & 0,06 & 0,07 & 0,007 \\
\hline
\end{tabular}

A análise das cerdas observadas nas fases de zoea e megalopa, demonstrou serem plumosas, cuspidadas, simples, paposas. No endito basal da maxila na zoea II, tanto no lobo proximal quanto no distal encontrou-se um conjunto de cerdas simples que se caracterizam pela presença, na sua extremidade distal, de uma pequena proeminência parecendo ser um orifício, quando observada no aumento de 1000 vezes (Fig. 7g). As cerdas plumosas e paposas são mais abundantes nos apêndices bucais, como maxila e maxilípodos, provavelmente com a função nos processos de seleção e triagem do alimento. Estes apêndices possuem também cerdas simples, porém em menor quantidade e provavelmente relacionam-se com a seletividade do alimento. As cerdas cuspidadas foram encontradas apenas na maxila e segundo maxilípodo.

\section{Morfologia dos estágios larvais}

\section{Zoea I (Figs 1-7a, 10a, 12a, 15a)}

Carapaça (Fig. 1a): globosa, com um espinho rostral, um dorsal, e dois espinhos laterais. O comprimento do espinho rostral corresponde praticamente a $2 / 3$ do espinho dorsal. Os olhos são sésseis.

Abdome (Fig. 2A): constituído por cinco somitos, desprovidos de apêndices. As margens póstero-laterais dos somitos abdominais terminam em pequenas projeções espiniformes. Os segundo e terceiro somitos possuem dois espinhos mediano-laterais, sendo os do segundo somito dirigidos para a parte anterior, enquanto que os do terceiro somito são dirigidos para a parte posterior. Os somitos possuem um par de cerdas simples (Fig. 2B) na região póstero dorsal, sendo que as cerdas dos primeiro e segundo somitos apresentam-se mais afastadas umas das outras. O telso (Fig. 2A) possui uma fileira com 35 cerdas simples na margem interna de cada ramo da furca (Fig. 2E), na face dorsal apresenta 40 cerdas simples (Fig. 2c). Presença de seis cerdas plumodenticuladas (Fig. 2d), dispostas simetricamente três a três, de cada lado de um entalhe mediano em sua margem interna, as quais equivalem-se em tamanho, pontos de inserção e número de cerdulas, respectivamente.

Antênula (Fig. 4 a): cônica, não segmentada com dois estetos e uma cerda simples (Figs 4 b, c).

Antena (Fig. 5 a): protopodito com processo espinhoso com duas fileiras de pequenos espinhos (Fig. 5 e), sendo que na face interna apresenta 13 e na externa nove. O exopodito possui duas cerdas simples subapicais (Fig. 5b, d) e a extremidade afilada (Fig. 5 c). 


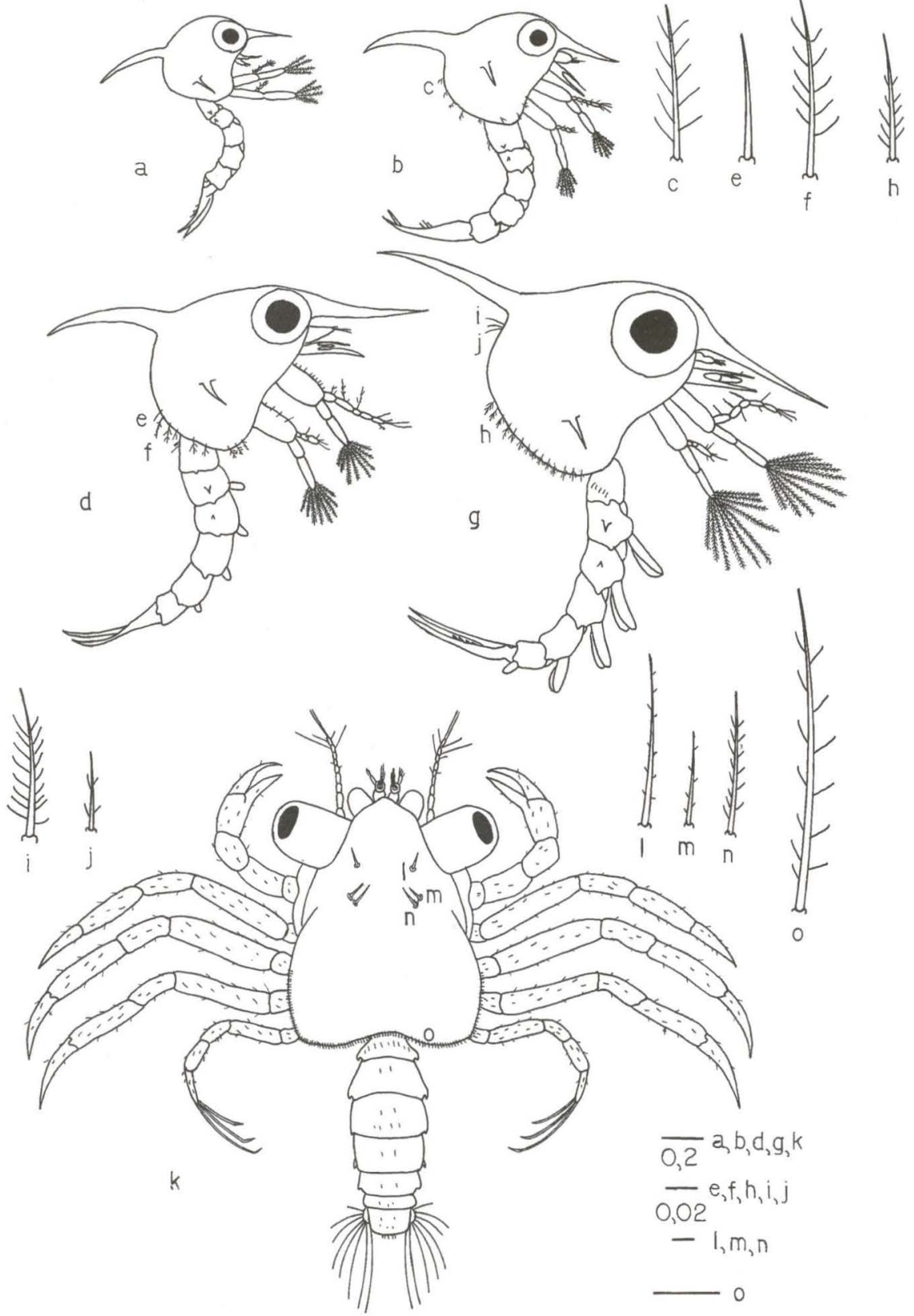

Fig. 1. Chasmagnathus granulata. (a) ZI; (b) ZII; (c) cerda paposa da carapaça da ZII; (d) ZIII; (e-f) cerdas simples e paposa da carapaça ZIII; (g) ZIV; (h-j) cerdas paposas da carapaça ZIV; (k) megalopa; (I-o) cerdas paposas carapaça; (a, b, d, g) vista lateral; (k) vista dorsal MI. 

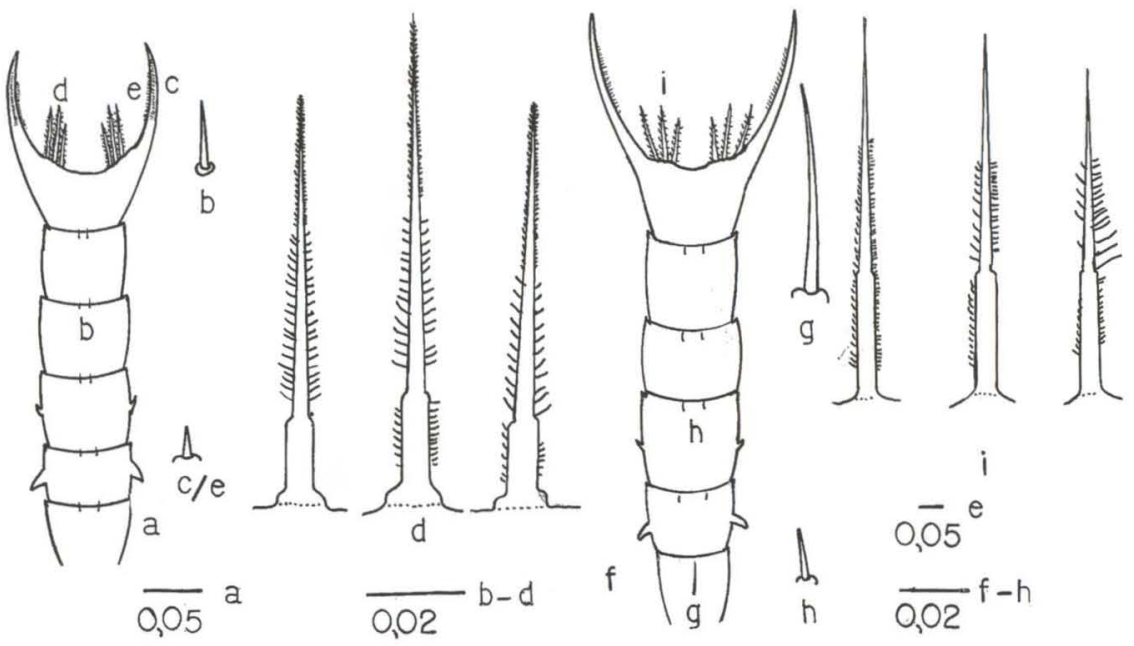

Fig. 2. Chasmagnathus granulata, abdome. (a) Zl; (b) cerdas simples dorsais dos somitos Zl; (c) cerda simples dorsal da furca Zl; (d) cerdas plumodenticuladas da furca Zl; (e) cerda simples ext. furca Zl; (f) ZlI; (g) cerda simples ZII; (h) cerda simples dorsal segundo ao quinto som. ZII; (i) cerdas plumodenticuladas furca ZII.

Mandíbula (Fig. 6 a): processo incisivo com sete projeções dentiformes, com tamanhos aproximados, que se estendem na forma de cristas na face externa. Processo molar com forma cilíndrica provido de cristas denteadas.

Maxílula (Fig. 7 a): Endito coxal com cinco cerdas, sendo uma simples (Fig. 7 d), e quatro paposas (Fig. 7 b, c, e, f). Endito basal com cinco cerdas, sendo uma simples (Fig. 7 j) e quatro paposas (Fig. 7 g-i, k). Endopodito bisegmentado com uma cerda simples (Fig. 7 a) no segmento proximal e cinco paposas no segmento distal, sendo uma subapical (Fig. 7 l) e quatro apicais (Fig. 7 m). Observou-se a presença de microtríquias no protopodito (Fig. 7 a).

Maxila (Fig. 10 a): Endito coxal bilobulado com duas cerdas paposas no lóbulo distal (Fig. 10 f, g) e quatro cerdas no lóbulo proximal, sendo uma cerda simples e três paposas (Fig. 10 b-e). Endito basal bilobulado com três cerdas paposas no lobo distal (Fig. $10 \mathrm{~m}$-o) e uma cerda simples e quatro paposas no lóbulo proximal (Fig. 10 h-k). Endopodito com duas cerdas paposas no lóbulo distal (Fig. 10 r, s) e duas cerdas paposas no lóbulo proximal, (Fig. 10 p, q). Exopodito (escafognatito) com quatro cerdas plumosas marginais (Fig. 10 a, t) e uma porção teminal afilada apresentando microtríquias.

Primeiro maxilípodo (Fig. 12 a): O basipodito com 10 cerdas na margem interna, dispostas no arranjo 3:1:3:3, sendo as duas cerdas proximais paposas e as demais simples (Fig. 12 b, c).

Endopodito pentasegmentado com 2, 2, 1,2, 5 cerdas do segmento proximal para o distal: duas cerdas paposas (Fig. 12 i); uma cerda proximal paposa e uma cerda distal simples (Fig. $12 \mathrm{~h}$ ); uma cerda paposa, duas cerdas simples, duas cerdas paposas, três cerdas simples (Fig. $12 \mathrm{f}$, g), respectivamente. Exopodito bissegmentado, com quatro longas cerdas plumosas natatórias no segmento distal (Fig. $12 \mathrm{~d}$ ). 

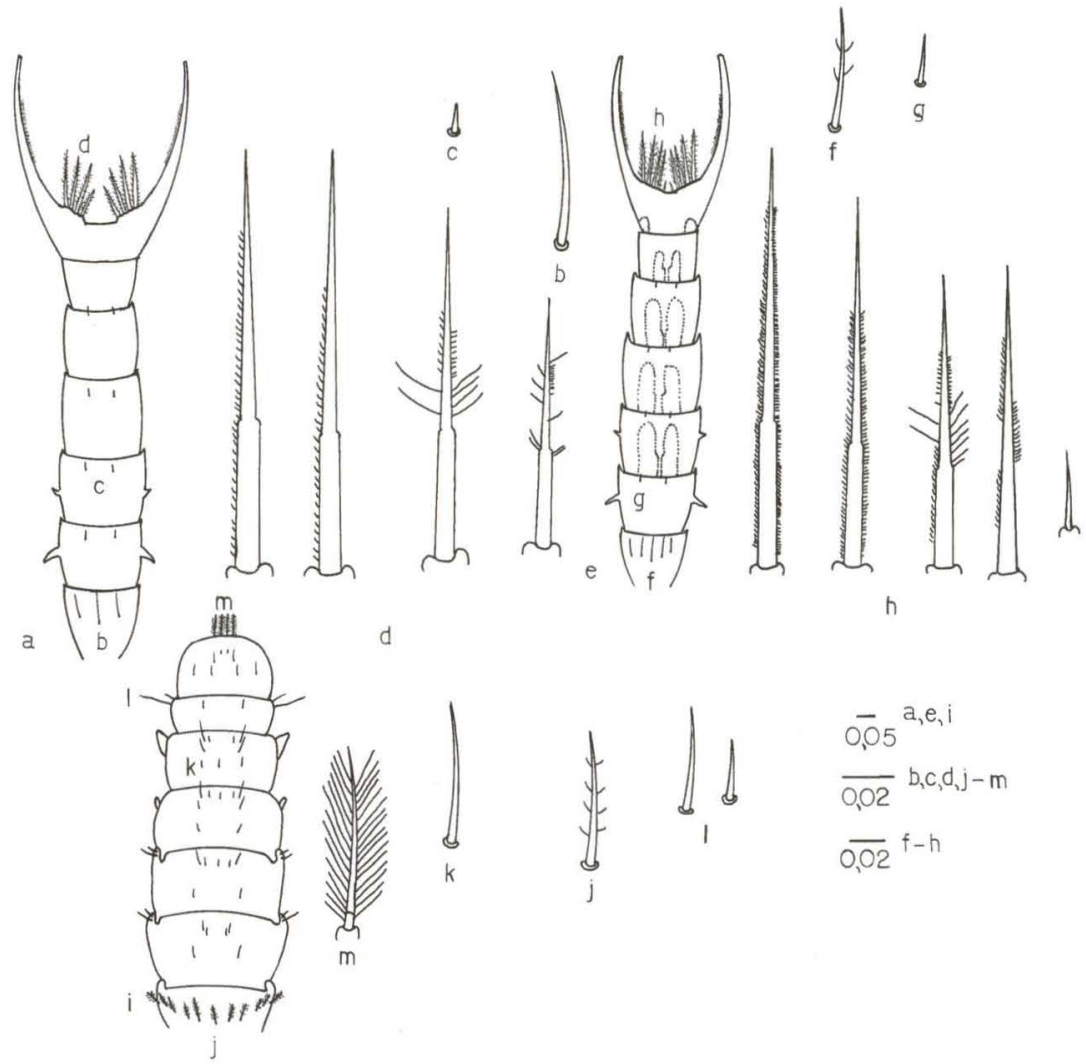

Fig. 3. Chasmagnathus granulata, abdome. (a) ZIII; (b) cerda simples dorsal 10 som. ZIII; (c) cerda simples dorsal segundo ao quinto som. ZIII; (d) cerdas plumodenticuladas da furca ZIII; (e) ZIV; (f) cerda paposa dorsal primeiro som ZIV; (g) cerda simples dorsal segundo ao quinto som. ZIV; (h) cerdas plumodenticuladas da furca ZIV; (i) MI; (j) cerda paposa dorsal MI, MII; (k) cerda simples quinto som. MI, MII; (I) cerda simples póstero-lateral sexto som. M; (m) cerda plumosa do telso MI, MII.

Segundo maxilípodo (Fig. 15 a): Basipodito com quatro cerdas simples na margem interna e dispostas no arranjo 1:1:1:1 (Fig. 15 b). Endopodito trisegmentado com 0, 1, 6 cerdas do segmento proximal para o distal: uma cerda paposa (Fig. 15 f); uma cerda paposa e cinco simples (Fig. 15 d). Exopodito não totalmente bisegmentado, com quatro longas cerdas natatórias plumosas no segmento distal (Fig. $15 \mathrm{c}$ ).

Zoea II (Figs 1 b, 2 f, 4 d, 5 f, 6 b, 12 j, 15 g)

Carapaça: (Fig. 1 b) globosa, com um espinho rostral, um espinho dorsal com comprimento equivalente a $2 / 3$ do rostral, e dois espinhos laterais. Com oito cerdas paposas em cada lado da região póstero-ventral (Fig. $1 \mathrm{c}$ ). Olhos pedunculados (Fig. 1 b).

Abdome: (Fig. 2 f) Semelhante ao da zoea, com uma cerda simples (Fig. 2 g), na região póstero-dorsal do primeiro somito abdominal. Apresenta um compri- 

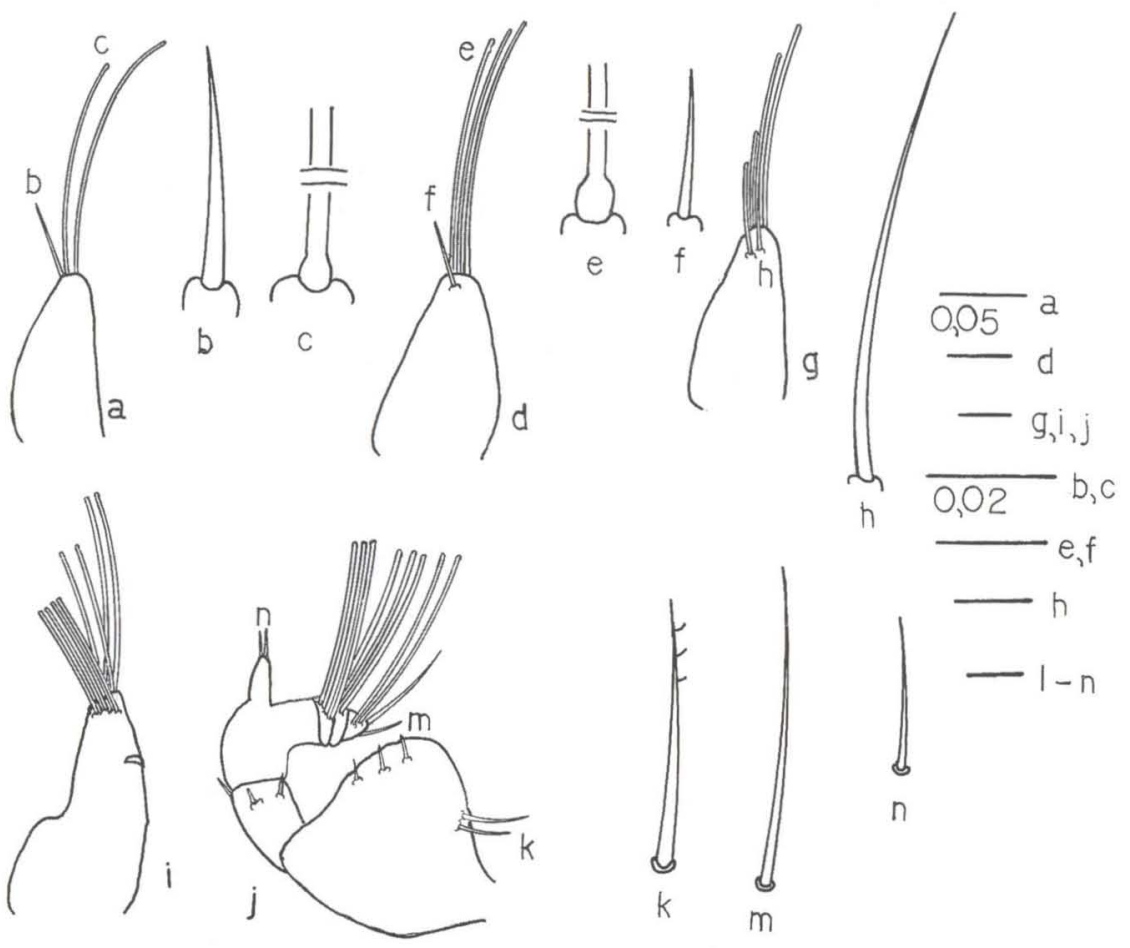

Fig. 4. Chasmagnathus granulata, antênula. (a) ZI; (b) esteto ZI; (c) cerda lisa ZI; (d) ZII; (e) esteto ZII; (f) cerda lisa ZII; (g) ZIII; (h) cerda simples ZIII; (i) ZIV; (j) MI, MII; (k) cerda paposa end. basal MI, MII; (I) cerda simples end. basal M; $(\mathrm{m})$ cerda simples endop. MI, MII; (n) cerda simples endop. MI, MII.

mento equivalente ao triplo do comprimento das cerdas dos outros somitos (Fig. 2 g). Nos demais somitos há um par de cerdas simples na região póstero-dorsal, sendo que as do segundo somito encontram-se um pouco mais afastadas entre si (Fig. 2 h). As margens póstero-laterais dos somitos abdominais terminam em pequenas projeções espiniformes. O telso possui uma fileira de 35 cerdas simples na margem lateral interna dos ramos da furca, As cerdas dorsais dos ramos da furca, à partir deste estágio, desaparecem. Presença de seis cerdas plumodenticuladas (Fig. 2 i) dispostas simetricamente três a três, de cada lado de um entalhe mediano, em sua margem interna. As cerdas de ambos os lados equivalem-se em tamanho, pontos de inserção e número de cérdulas.

Antênula: (Fig. 4 d) semelhante á da zoea I, com três estetos e uma cerda simples (Fig. 4 e, f).

Antena: (Fig. $5 \mathrm{f}$ ) protopodito com processo espinhoso com uma fileira de pequenos espinhos, sendo que na face interna apresenta 12(14) e na externa 15(17) (Fig. 5 j). Exopodito semelhante a zoea I (Fig. 5 g-i).

Mandíbula: (Fig. 6 b) processo incisivo com 10 projeções dentiformes com forma e tamanhos aproximados, processo molar com forma cilíndrica. 


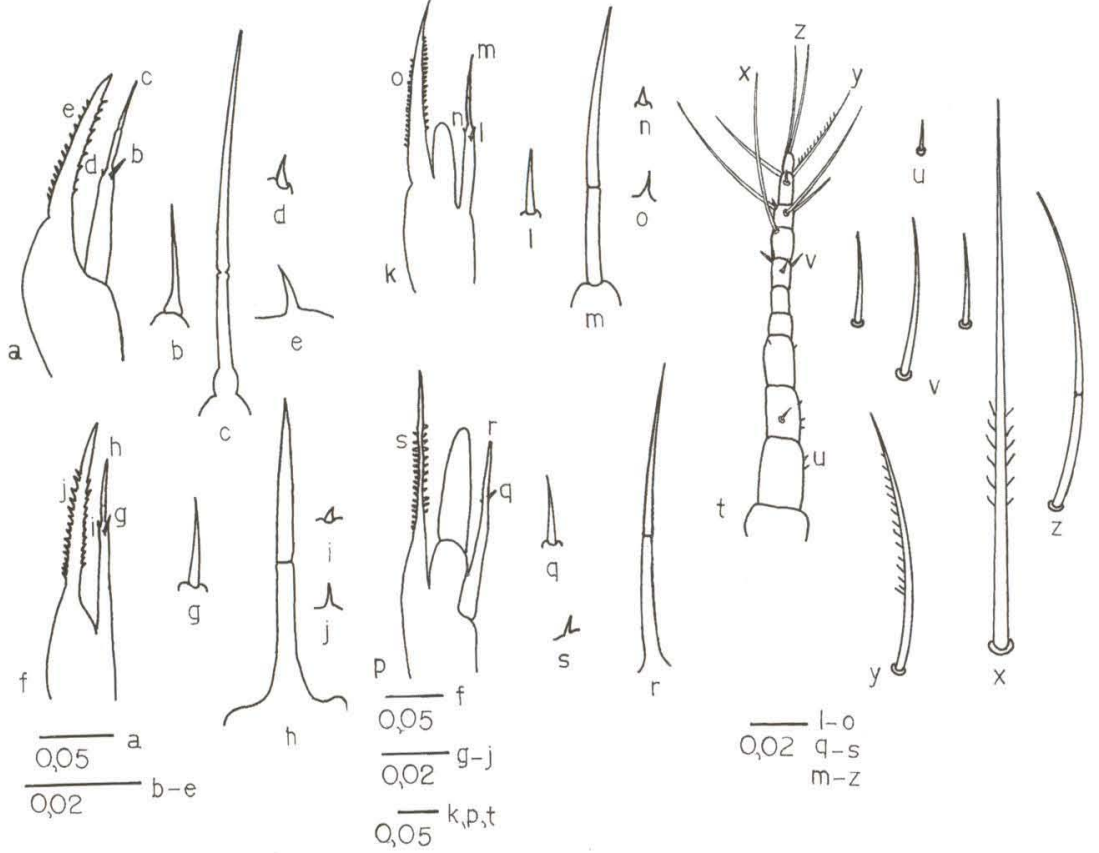

Fig. 5. Chasmagnathus granulata, antena. (a) Zl; (b) cerda simples exop. Zl; (c) ext. exop. Zl; (d) cerda simples exop. Zl; (e) espinho protop. Zl; (f) Zll; (g) cerda simples exop. ZlI; (h) ext. exop. ZII; (i) cerda simples exop. ZII; (j) espinho protop. ZII; (k) ZIII; (I) cerda simples exop. ZIII; (m) ext. exop. ZIII; (n) cerda simples exop. ZIII; (o) espinho protop. Z III, (p) ZIV; (q, r) cerda simples exop. ZIV; (s) espinho protopodito ZIV; (t) MI, MII; (u) cerda simples primeiro segmento pedúnculo MI, MII; (v) cerdas simples terceiro seg. flagelo MI, MII; (x) cerda paposa quinto seg. flagelo $\mathrm{MI}, \mathrm{MII}$; $(\mathrm{y})$ cerda plumosa sétimo seg. flagelo $\mathrm{MI}, \mathrm{MII}$; $(\mathrm{z}$ ) cerda simples oitavo seg. flagelo MI, MII.

Maxílula: (Fig. 7 a) endito coxal com cinco cerdas, sendo uma simples e quatro paposas (Fig. 7 b-f). Endito basal com duas cerdas simples e cinco paposas (Fig. 7 $\mathrm{g}-\mathrm{m})$. Endopodito bisegmentado; segmento proximal com uma cerda simples e distal com cinco, sendo uma simples subapical e as demais apicais paposas (Fig. $7 \mathrm{n}, \mathrm{o}$ ).

Maxila: (Fig. 10a) endito coxal bilobulado com quatro cerdas simples no lóbulo proximal (Fig. 10 b) e 3(4) paposas no distal. Endito basal bilobulado, com 5(6) cerdas paposas no lóbulo proximal, (Fig. 10 c), e 4(5) paposas no lóbulo distal (Fig. 10 d). Endopodito com quatro cerdas paposas, duas no lóbulo proximal e duas no distal (Fig. 10 e, f). Exopodito (escafognatito) com cinco cerdas plumosas marginais (Fig. 10 a, g) e três plumosas na porção terminal (Fig. $10 \mathrm{a}, \mathrm{h}$ ). Entre as porções proximal e distal do exopodito, no endopodito e enditos basal e coxal observou-se a presença de microtríquias na superfície lateral destes enditos (Fig. 10 a).

Primeiro maxilípodo: (Fig. $12 \mathrm{j}$ ) basipodito com três cerdas paposas e sete simples na margem interna dispostas no arranjo 3:3:1:1 (Fig. $12 \mathrm{k}-\mathrm{m}$ ). Endopodito pentasegmentado com, respectivamente 2, 2, 1, 2, 5 cerdas do segmento proximal para o distal: duas cerdas lisas (Fig. 12 r); uma cerda lisa e uma paposa; uma cerda 

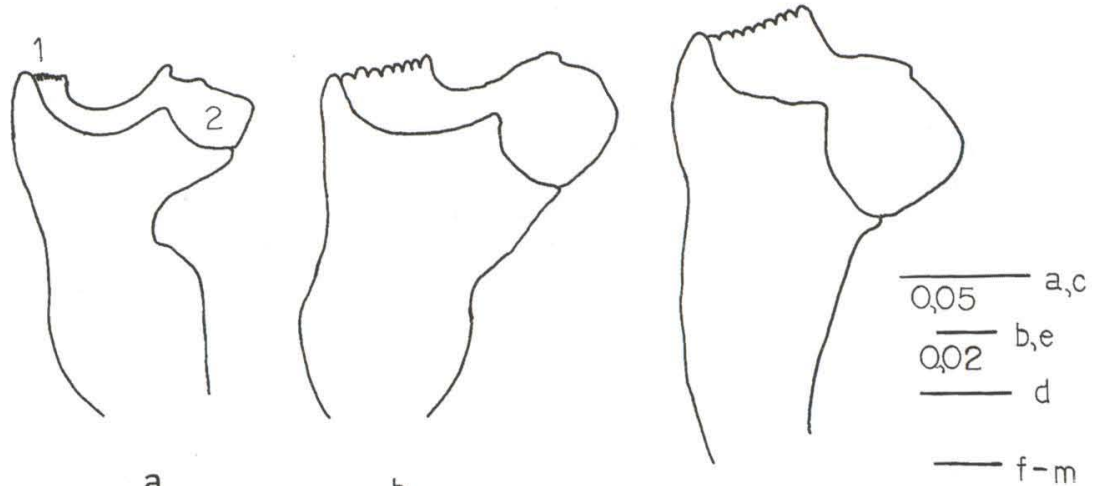

a

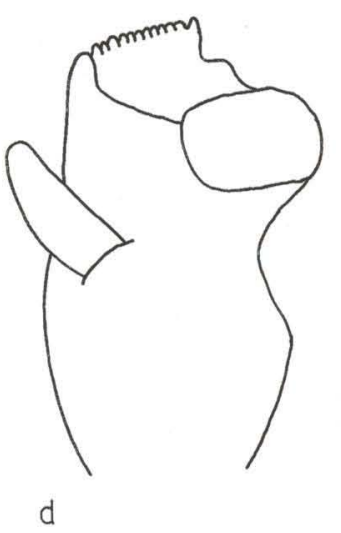

$b$

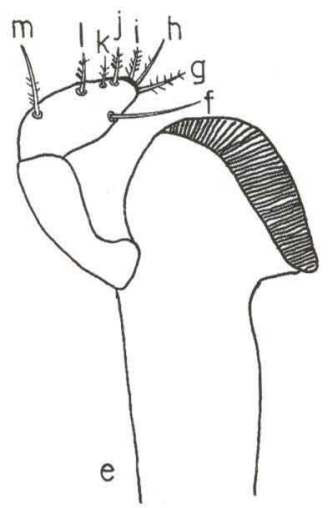

C
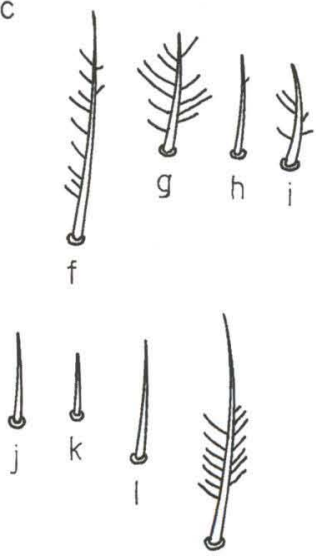

m

Fig. 6. Chasmagnathus granulata, mandíbula. (a) ZI; (b) ZII; (c) ZIII; (d) ZIV; (e) MI, MII; (f-i, m) cerdas paposas art. distal palpo MI, MII; (j-I) cerdas simples art. distal palpo M; (1) processo incisivo MI, MII; (2) processo molar MI, MII.

paposa; duas cerdas paposas; três cerdas simples e as demais paposas (Fig. 12p, q). Exopodito bisegmento, com o segmento distal provido de seis cerdas plumosas natatórias, sendo as quatro cerdas centrais de tamanho equivalente e maiores que as cerdas periféricas que também equivalem-se entre si (Fig. 12 n, o).

Segundo maxilípodo: (Fig. $15 \mathrm{~g}$ ) basipodito com quatro cerdas marginais paposas dispostas no arranjo 1:1:2 (Fig. 15 h, i). Endopodito trisegmentado, com 0, 1 e 6 cerdas, do segmento proximal para o distal: uma cerda paposa (Fig. 15 f); uma cerda paposa e cinco simples (Fig. 15 d). Exopodito com uma constrição mediana, não totalmente segmentado, com seis longas cerdas plumosas no segmento distal, sendo as cerdas centrais de tamanho equivalente e maiores que as cerdas periféricas que equivalem-se entre si (Fig. $15 \mathrm{j}, \mathrm{k}$ ).

Zoea III (Figs 1 d, 3 a, 4 g, 5 k, 6 c, 8 a, 11 a, 13 a, 15 m)

Carapaça: (Fig. 1 d) globosa, com espinho rostral, espinho dorsal e dois espinhos laterais, sendo que o comprimento do espinho dorsal corresponde a 2/3 do 

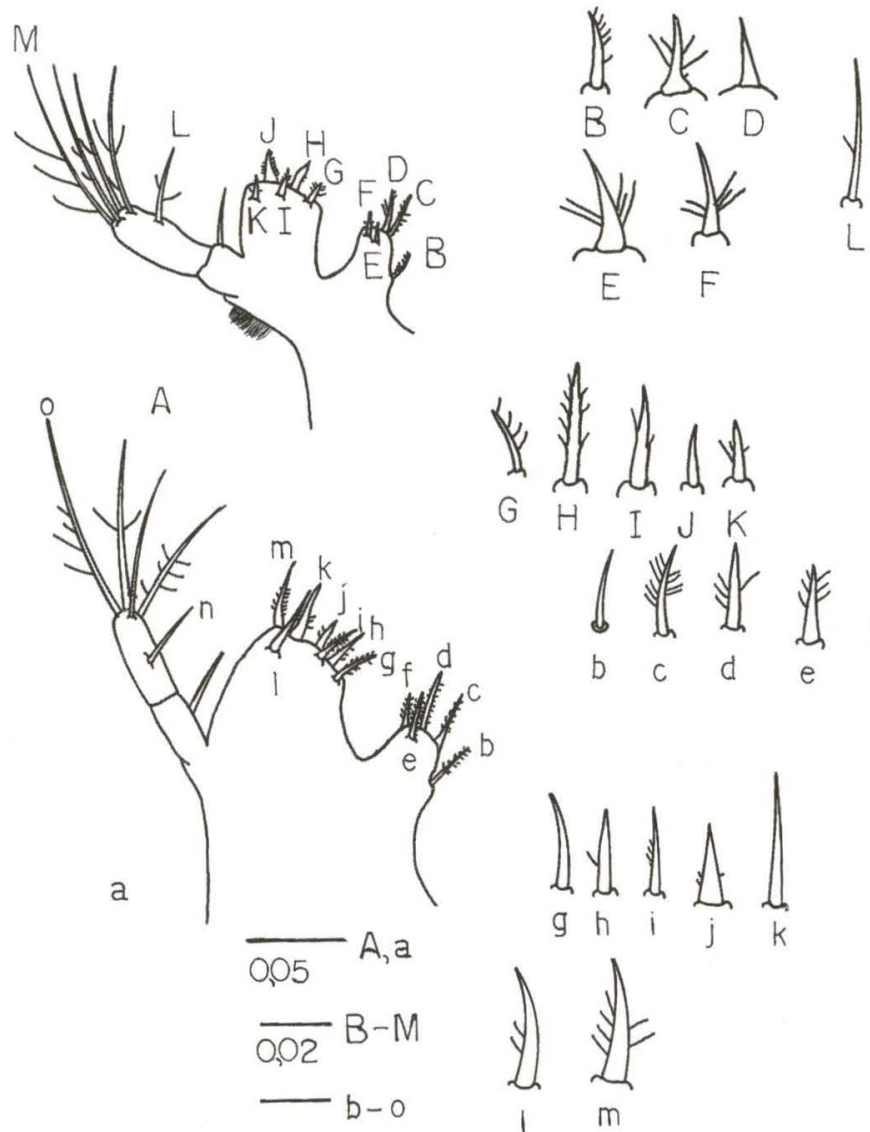

E F
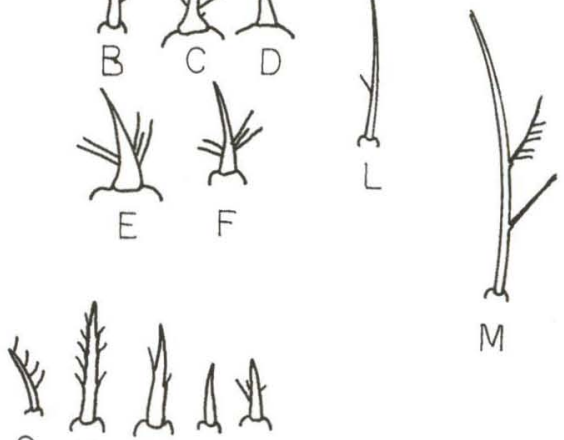

M

G

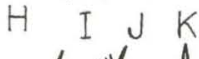
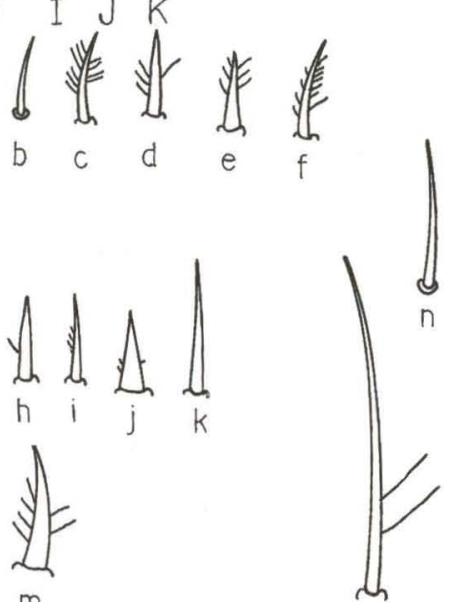

Fig. 7. Chasmagnathus granulata, maxílula. (a) Zl; (b-f) cerdas paposas end. coxal Zl; (d) cerda simples end. coxal Zl; ( $\mathrm{g}$-i, k) cerdas paposas end. coxal Zl; (j) cerda simples end. basal Zl; (I-m) cerdas paposas endop. ZI; (a) ZII; (c-f) cerdas paposas end. basal ZII; (b) cerdas simples end. basal Z II; (h-j, I- m) cerdas paposas end. coxal ZII; $(\mathrm{g}, \mathrm{k})$ cerdas simples end. coxal ZII; (n) cerda simples endop. Z II; (o) cerda paposas endop. Z II.

espinho rostral. Apresenta oito cerdas na região póstero ventral, sendo uma simples (Fig. 1 e) e sete paposas (Fig. 1 f). Olhos pedunculados (Fig. 1 d).

Abdome: (Fig. 3 a) constituído por seis somitos. As margens póstero-laterais dos somitos abdominais terminam em pequenas projeções espiniformes. Os segundo e terceiro somitos possuem dois espinhos mediano-laterais, sendo os do segundo somito dirigidos para a parte anterior, com base larga e ápice arredondado, enquanto que os do terceiro somito são dirigidos para a parte posterior, com base estreita e ápice afilado. O primeiro somito possui três cerdas simples mediano-dorsais (Fig. 3 b), o sexto somito é desprovido de cerdas e os demais possuem um par de cerdas simples póstero-dorsais (Fig. 3 c). O telso possui uma fileira de 40(38) cerdas 

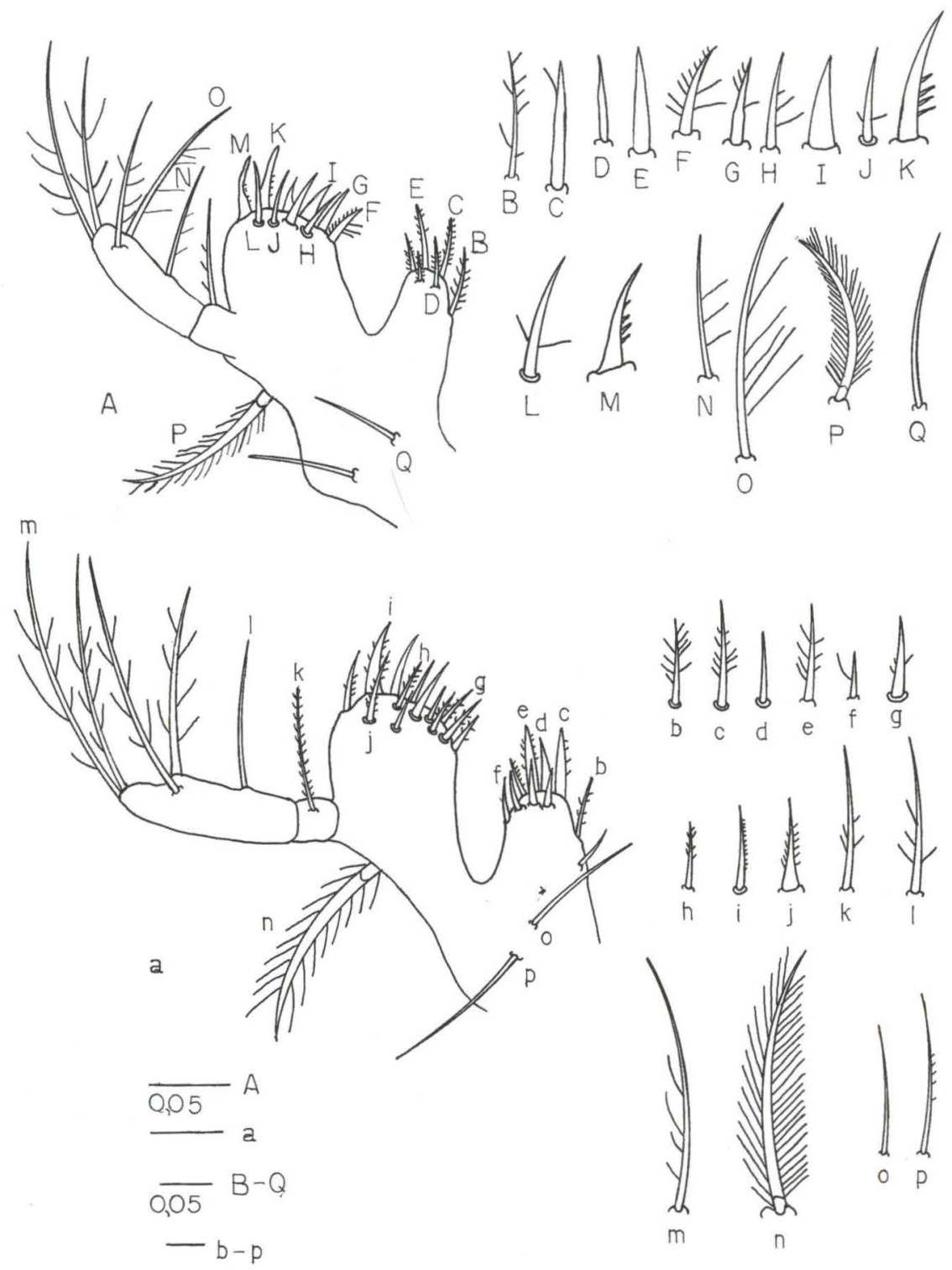

Fig. 8. Chasmagnathus granulata, maxilula. (a) ZIII; (b-d) cerdas plumosas end. coxal ZIII; (e) cerda simples end. coxal ZIII; (f-h, j-m) cerdas plumosas end. basal ZIII; (i) cerda simples end. coxal Z III; (n-o) cerdas paposas endop. ZIII; (p) cerdas paposas protopodito ZIII; (q) cerda simples protop. ZIII; (a) ZIV; (b-c, e-f) cerdas paposas end. coxal ZIV; (d) cerda simples end. coxal ZIV; (g-j) cerdas paposas end. basal ZIV; (k) cerda paposas art. prox. endop. ZIV; (I-m) cerdas simples e cerda paposa art. distal endop. ZIV; (n) cerda plumosa protopodito ZIV; (o) cerda lisa; $(p)$ cerda plumosa protopodito Z IV. 


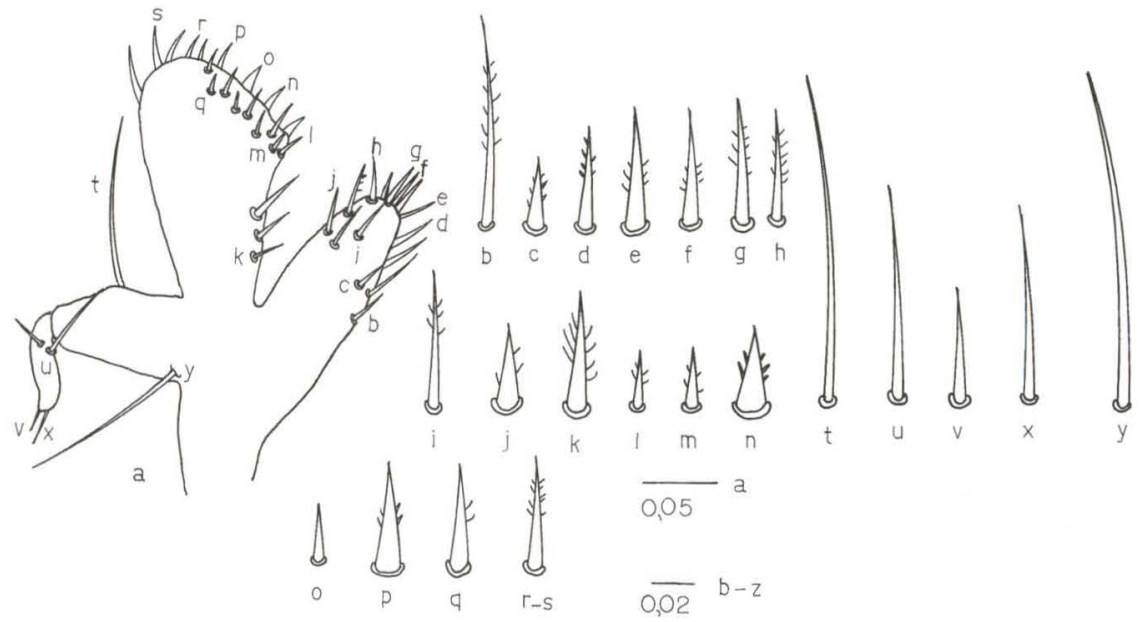

Fig. 9. Chasmagnathus granulata, maxílula. (a) MI, MII; (b-j) cerdas paposas end. coxal MI, MII; (k-l, q-s) cerdas paposas end. basal MI, MII; ( $r-y)$ cerdas simples endop. MI, MII; (o) cerda simples end. basal MI, MII; (m-p) cerdas cuspidadas end. basal MI, MII.

simples na margem lateral interna, de cada ramo da furca (Fig. 3 a). Presença de oito cerdas plumodenticuladas (Fig. 3 d) dispostas simetricamente quatro a quatro, de cada lado de um entalhe mediano em sua margem interna. As cerdas de ambos os lados equivalem-se em tamanho, pontos de inserção e número de cerdulas.

Antênula: (Fig. 4 g) semelhante à zoea II, possuindo três estetos distais e um esteto e uma cerda simples subdistal (Fig. 4 h).

Antena: (Fig. $5 \mathrm{k}$ ) protopodito com processo espinhoso, com duas fileiras de pequenos espinhos (Fig. 5 o), sendo que na face interna apresenta 16(18) e na externa 19(18). Exopodito semelhante a zoea II (Fig. 5 l-n) Endopodito surgindo como um pequeno bulbo (Fig. 5 k).

Mandíbula: (Fig. 6 c) processo incisivo com nove projeções dentiformes, processo molar com forma cilíndrica.

Maxílula: (Fig. 8 a) endito coxal com 6(7) cerdas, sendo uma cerda simples e as demais paposas (Fig. 8 b-e). Endito basal com 10(13) cerdas, sendo a cerda uma simples e as demais paposas (Fig. $8 \mathrm{f}$-m). Endopodito bisegmentado com uma cerda paposa no segmento proximal (Fig. 8 a, n) e cinco cerdas paposas no segmento distal (Fig. 8 a, o). Protopodito com uma cerda plumosa lateral (Fig. 8 p) e duas cerdas simples na superfície dorsal (Fig. 8 q).

Maxila: (Fig. 11 a) endito coxal bilobulado com 7(8) cerdas, possuindo o lóbulo proximal 4(5) cerdas paposas (Fig. 11 b), e três cerdas paposas no distal. Endito basal bilobulado com 5(6) cerdas no lóbulo proximal, sendo uma cerda simples e as demais paposas (Fig. 11c, d), e 5(6) cerdas paposas no lóbulo distal (Fig. 11a). Endopodito com quatro cerdas paposas, duas no lóbulo proximal e duas no distal (Fig. 11e, f). Exopodito (escafognatito) em forma de leque, com 15(18) cerdas plumosas marginais (Fig. $11 \mathrm{~g}$, h). Presença de microtríquias nas faces lateral e mesial do endito coxal e endopodito, bem como na porção terminal do exopodito. 


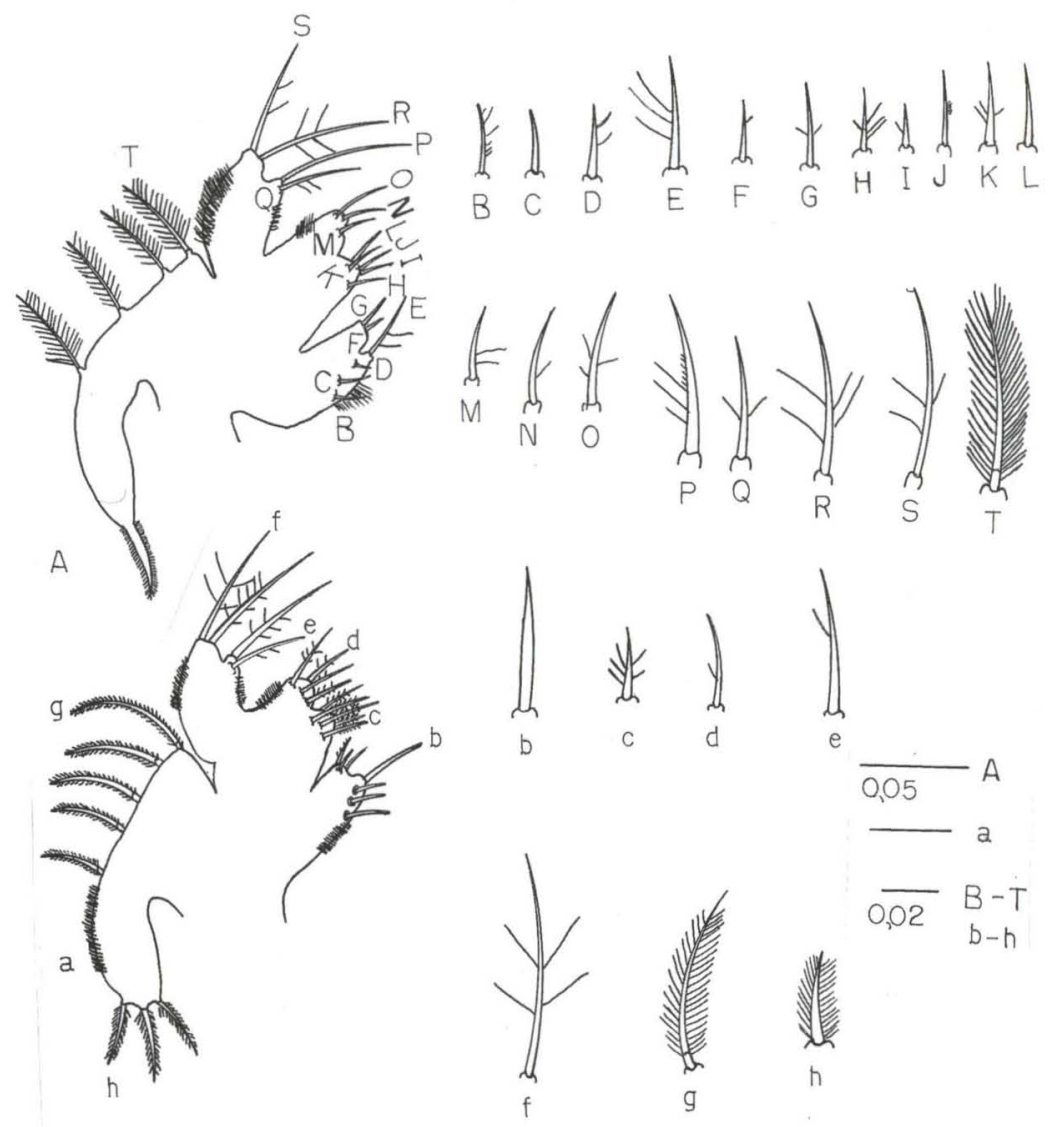

Fig. 10. Chasmagnathus granulata, maxila, (a) Zl; (b, d-g) cerdas paposas end. coxal Zl; (c) cerda simples end. coxal Zl; ( $h-k, m-0)$ cerdas paposas end. basal $\mathrm{Zl}$; (I) cerda simples end. basal ZI; (p-s) cerdas paposas endop. Zl; (t) exop. ZI; (a) ZII; (b) cerda simples end. coxal ZII; (c-d) cerdas paposas end. basal ZII; (e-f) cerdas paposas endop. ZII; (g-h) cerdas plumosas exop. ZII.

Primeiro maxilípodo: (Fig. 13a) basipodito com uma cerda simples e nove paposas na margem interna, dispostas no arranjo 3:3:2:1:1 (Fig. 13b, c). Endopodito pentasegmentado com 2, 2, 2, 2 e 5 cerdas do segmento proximal para o distal: uma cerda simples e uma paposa; nos quatro primeiros segmentos, respectivamente, e no quinto segmento cinco cerdas paposas (Fig. 13 e,f). Exopodito bisegmentado, com oito longas cerdas plumosas natatórias no segmento distal(Fig. 13a, d).

Segundo maxilípodo: (Fig. 15m) basipodito com quatro cerdas paposas dispostas no arranjo 1:1:1:1 (Fig. 15n, o, p, q). Endopodito trisegmentado com 0, 1 e 6 cerdas, do segmento proximal para o distal. Presença de uma cerda paposa (Fig. $15 \mathrm{~s}$ ) no terceiro segmento e as demais simples. Exopodito bisegmentado, com oito longas cerdas plumosas natatórias no segmento distal (Fig. $15 \mathrm{~m}, \mathrm{r}$ ). 

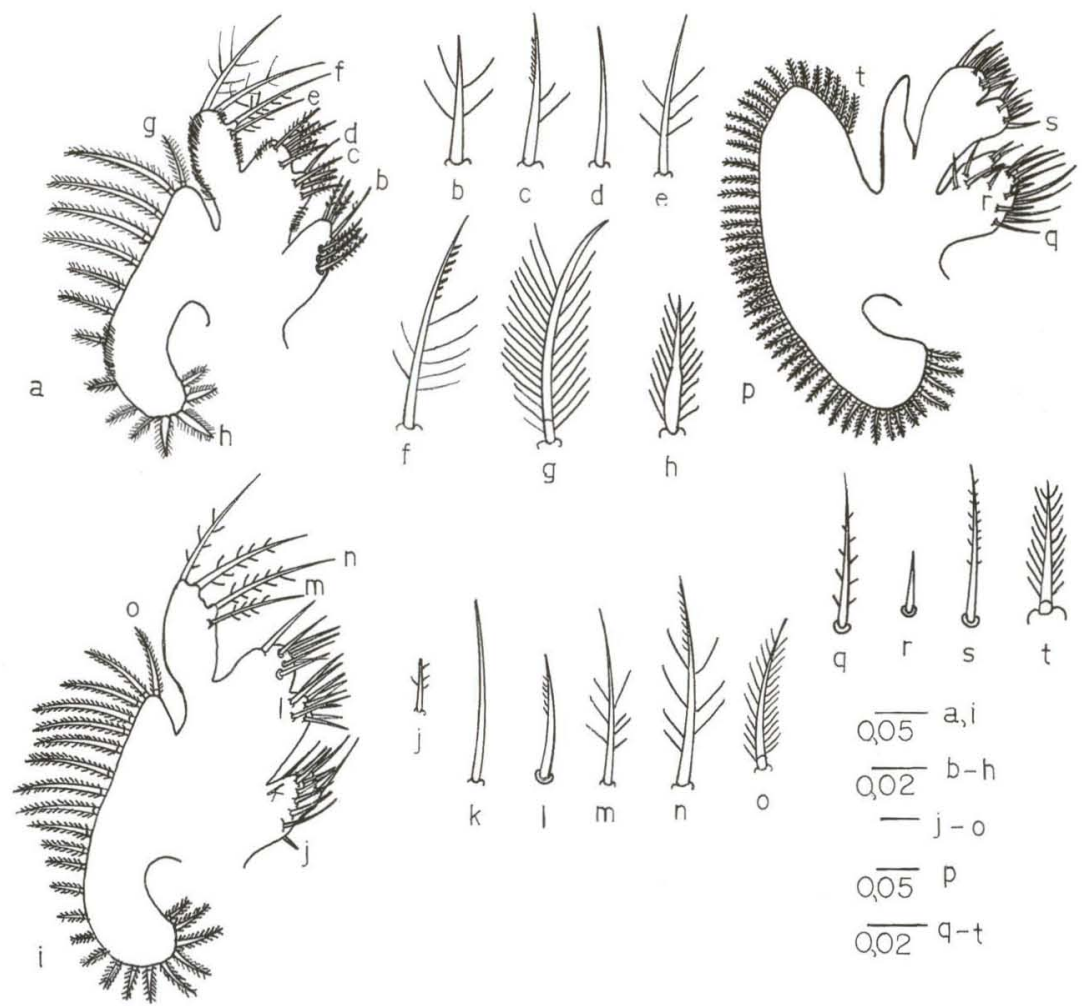

Fig. 11. Chasmagnathus granulata, maxila. (a) ZIII; (b) cerda paposa end. coxal Z III; (c) cerda paposa end. basal ZIII; (d) cerda simples end. basal ZIII; (e-f) cerdas paposas endop. ZIII; (g-h) cerdas plumosas exop. ZIII; (i) ZIV; (j) cerda paposa end. coxal ZIV; (k) cerda simples end. coxal ZIV; (I) cerda paposa end. basal ZIV; (m-n) cerdas paposa endop. ZIV; (o) cerda plumosa exop. ZIV; (p) MI, MII; (q) cerda paposa end. coxal MI, MII; (r) cerda simples end. coxal MI, MII; (s) cerda paposa end. basal MI, MII; (t) cerda plumosa exop. MI, MII.

\section{Zoea IV (Figs $1 \mathrm{~g}, 3 \mathrm{e}, 4 \mathrm{i}, 5$ p, 6 d, 8 a, 11 i, $13 \mathrm{~g}, 16$ a, 18 pl2-pl5, $18 \mathrm{u}$ )}

Carapaça: (Fig. $1 \mathrm{~g}$ ) globosa, com um espinho dorsal e um espinho rostral com tamanhos equivalentes e dois espinhos laterais. Presença de 14 cerdas paposas na posterior (Fig. $1 \mathrm{~h}$ ). Presença de três cerdas paposas localizadas logo abaixo do ângulo interno do espinho dorsal (Fig. 1i, j).

Abdome (Fig. 3 e): presença de um par de bulbos de pleópodos nos segundo a quinto somitos e um par de bulbos de urópodos no sexto somito (Fig. 3 e). O primeiro somito possui cinco cerdas paposas mediano-dorsais, sendo que a cerda central apresenta-se um pouco maior do que as cerdas pares laterais (Fig. $3 \mathrm{e}, \mathrm{f}$ ), o sexto somito é desprovido de cerdas e os demais somitos possuem um par de cerdas simples mediano-dorsais (Fig. 3 e, g). O telso possui uma fileira de 40(45) cerdas simples na margem lateral interna de cada ramo da furca. Presença de dez cerdas plumodenticuladas dispostas simetricamente cinco a cinco, em sua margem interna. As cerdas de ambos os lados são equivalentes em tamanho, forma e número de cerdulas (Fig. 3 h). 

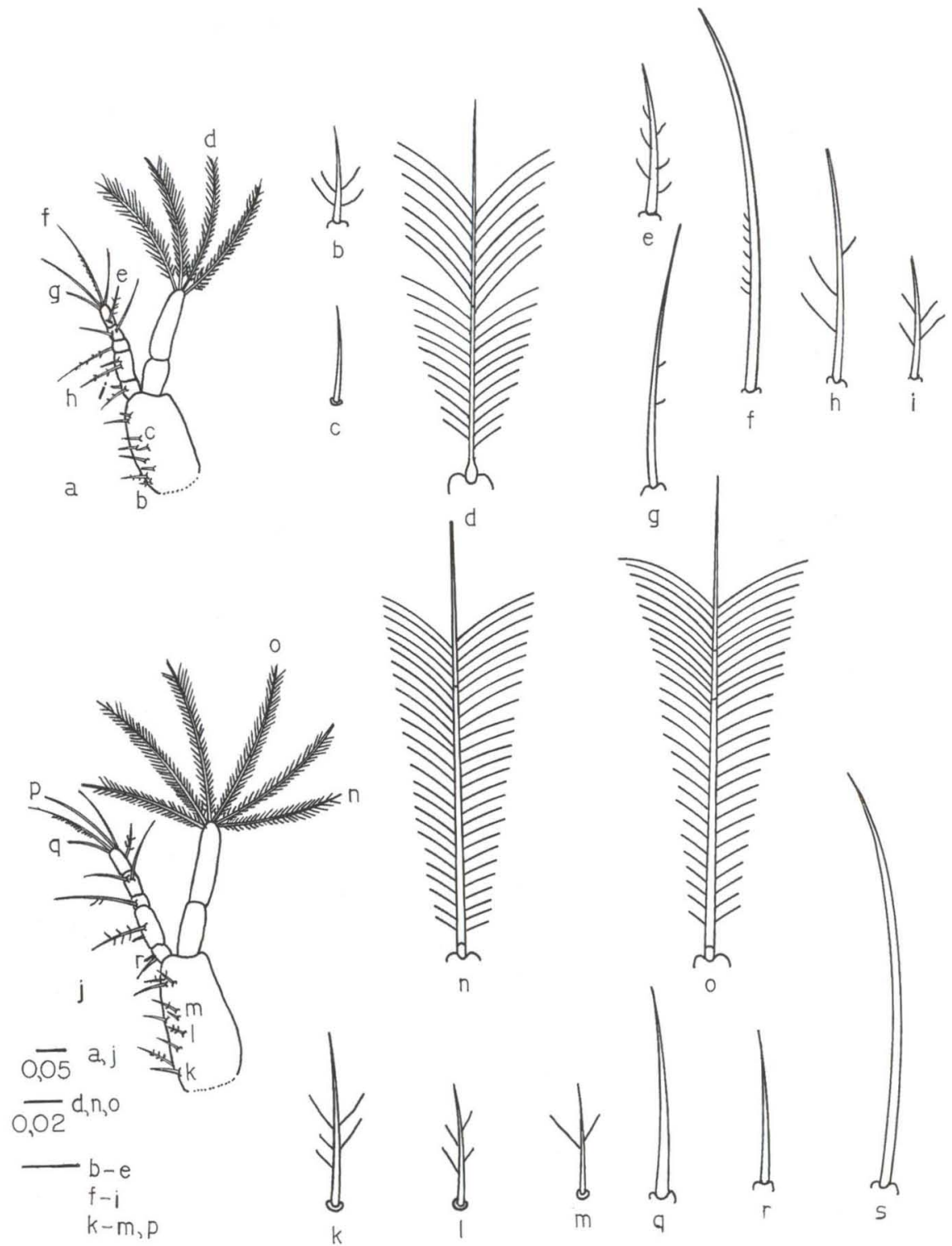

Fig. 12. Chasmagnathus granulata, primeiro maxilipodo. (a) Zl; (b) cerda paposa basipodito $\mathrm{ZI}$; (c) cerda simples basipodito ZI; (d) cerda plumosa exop. ZI; (e-i0 cerdas paposas endop. $\mathrm{ZI}$; (j) ZII; (k-m) cerdas paposas basipodito ZII; (n-o) cerdas plumosas exop. Zll; (p-r) cerdas simples endop. ZII. 


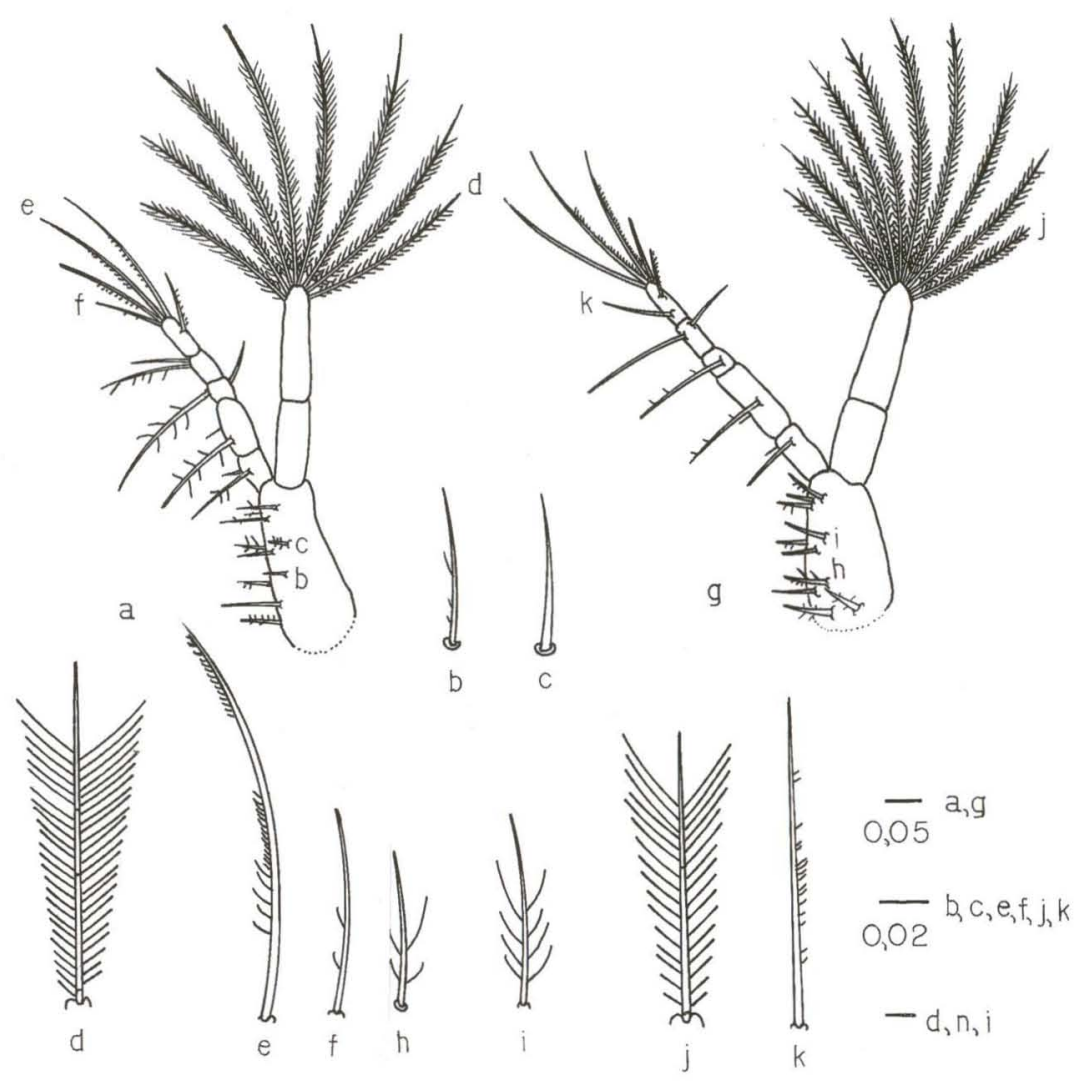

Fig. 13. Chasmagnathus granulata, primeiro maxilipodo. (a) ZIII; (b) cerda plumosa basipodito ZIII; (c) cerda simples basipodito ZIII; (d) cerda paposas exop. ZII; (e-f) cerdas plumosas endop. ZIII; (g) ZIV; (h-i) cerdas paposas end. basal ZIV; (j) cerda plumosa exop. ZIV; (k) cerda paposa endop. ZIV.

Antênula: (Fig. 4 i) Endopodito rudimentar. Exopodito com oito estetos, dispostos em dois níveis.

Antena (Fig. 5 p) processo espinhoso do protopodito com uma fileira de 16(14) espinhos na margem externa e 10(12) espinhos na margem interna (Fig. 5 p, s). Exopodito semelhante ao estágio anterior (Fig. 5 q, r). Endopodito bisegmentado desprovido de cerdas (Fig. 5 p).

Mandíbula (Fig. 6 d) Presença de um pequeno palpo lateral liso, processo incisivo com 13 projeções dentiformes, processo molar com forma cilíndrica, provido de cristas denteadas. Possui um pequeno palpo lateral desprovido de cerdas.

Maxílula: (Fig. 8 a) endito coxal com 10(11) cerdas, sendo uma cerda simples e as demais paposas (Fig. 8 b-f). Endito basal com 13(15) cerdas, sendo as $4(5)$ primeiras cerdas simples e as demais paposas (Fig. 8 g-j). Endopodito bisegmentado com uma cerda paposa no segmento proximal (Fig. 8 k) e quatro 


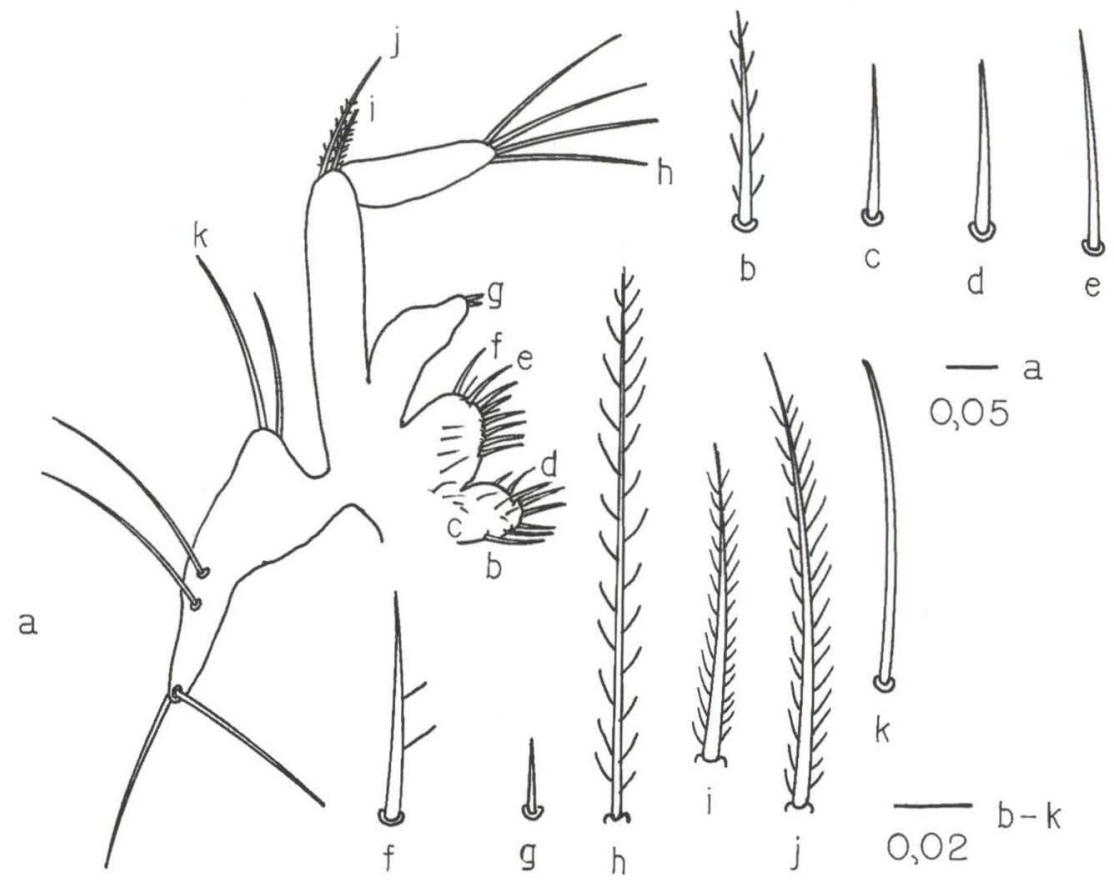

Fig. 14. Chasmagnathus granulata, primeiro maxilípodo. (a) MI, MII; (b) cerda paposa end. coxal MI, MII; (c-d) cerdas simples end. coxal MI, MII; (e) cerda simples end. basal MI, MII; (f) cerda paposa end. basal MI, MII; (g) cerda simples endop. MI, MII; $(\mathrm{h}-\mathrm{i})$ cerdas paposas exop. MI, MII, (k) cerda simples epipodito MI, MII.

cerdas paposas e uma simples no segmento distal (Fig. $8 \mathrm{l}, \mathrm{m}$ ). Protopodito com uma cerda plumosa lateral (Fig. $8 \mathrm{n}$ ) e uma cerda simples e uma paposa na superfície dorsal (Fig. 8 o, p).

Maxila: (Fig. 11 i) endito coxal bilobulado com 5(7) cerdas paposas no lóbulo proximal (Fig. $11 \mathrm{j}$ ), e 5(6) cerdas simples no distal (Fig. 11k) e as demais paposas (Fig. 11 1). Endito basal bilobulado com 9(8) cerdas paposas no lóbulo proximal (Fig. 11 1), 7(9) cerdas simples no lóbulo distal (Fig. 11 i). Endopodito bilobulado com duas paposas no lóbulo distal e duas paposas no proximal (Fig. $11 \mathrm{~m}, \mathrm{n}$ ). Exopodito (escafognatito) em forma de leque, possuindo 24(28) cerdas plumosas marginais (Fig. $11 \mathrm{i}, \mathrm{o}$ ).

Primeiro maxilípodo: (Fig. $13 \mathrm{~g}$ ) basipodito com oito cerdas paposas e duas simples dispostas no arranjo 2:2:3:3 (Fig. $13 \mathrm{~h}$, i). Endopodito pentasegmentado com 2, 2, 1, 2 e 6 cerdas do segmento proximal para o distal: duas cerdas simples; uma cerda paposa e uma simples; uma cerda paposa; duas cerdas simples; seis cerdas paposas (Fig. 13 k). Exopodito bisegmentado, com 10 cerdas plumosas natatórias no segmento distal (Fig. 13 g, j).

Segundo maxilípodo: (Fig. 16 a) basipodito com quatro cerdas paposas dispostas no arranjo 1:1:1:1. Endopodito trisegmentado com 0,1 e 6 cerdas do 
segmento proximal para o distal:1(2) cerda paposa; uma cerda paposa e cinco simples (Fig. 16 c). Exopodito bisegmentado, 10 cerdas plumosas natatórias no segmento distal (Fig. 16 b).

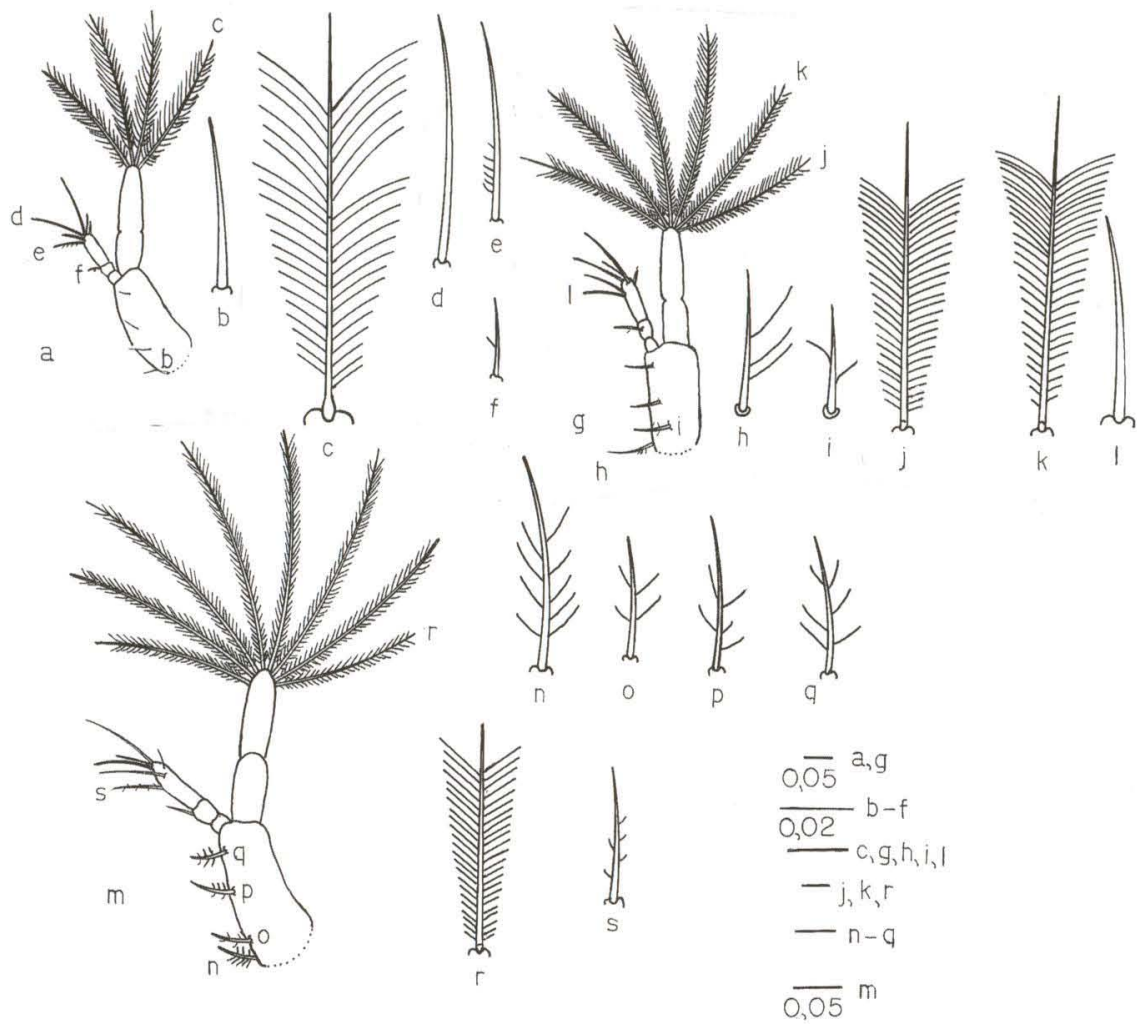

Fig. 15. Chasmagnathus granulata, segundo maxilípodo. (a) Zl; (b) cerda simples basipodito Zl; (c) cerda plumosa exop. Zl; (d) cerda simples endop. Zl; e, (f) cerdas paposas endop. Zl; (g) ZII; (h-i) cerdas paposas basipodito ZII; (j-k) cerdas plumosas exop. ZII; (I) cerda simples endop. ZII; (m) ZIII; (n-q) cerdas basipodito ZIII; (r) cerda plumosa exop. ZIII; (s) cerda paposa endop. ZIII.

Megalopa I (Figs 1k, 3i, 4j, 5t, 6e, 9a, 11p, 14a, 16d, 17a, 18pl2-pl5, 18u, 19p1-p5)

Carapaça: (Fig. 1 k) subquadrangular, dorsalmente convexa com comprimento um pouco maior do que a largura. Na região dorsal apresenta minúsculas cerdas simples esparsas e, nas regiões póstero-laterais e posterior, 70 pequenas cerdas paposas, dispostas regularmente nas margens. Apresenta, ainda três pares de cerdas paposas dorsais na região proximal das órbitas (Fig. 1 1-o). O rostro apresenta-se como uma projeção defletida não ultrapassando o terceiro segmento do pedúnculo antenal. Os olhos são pedunculados. O terceiro maxilípodo, os pereió- 


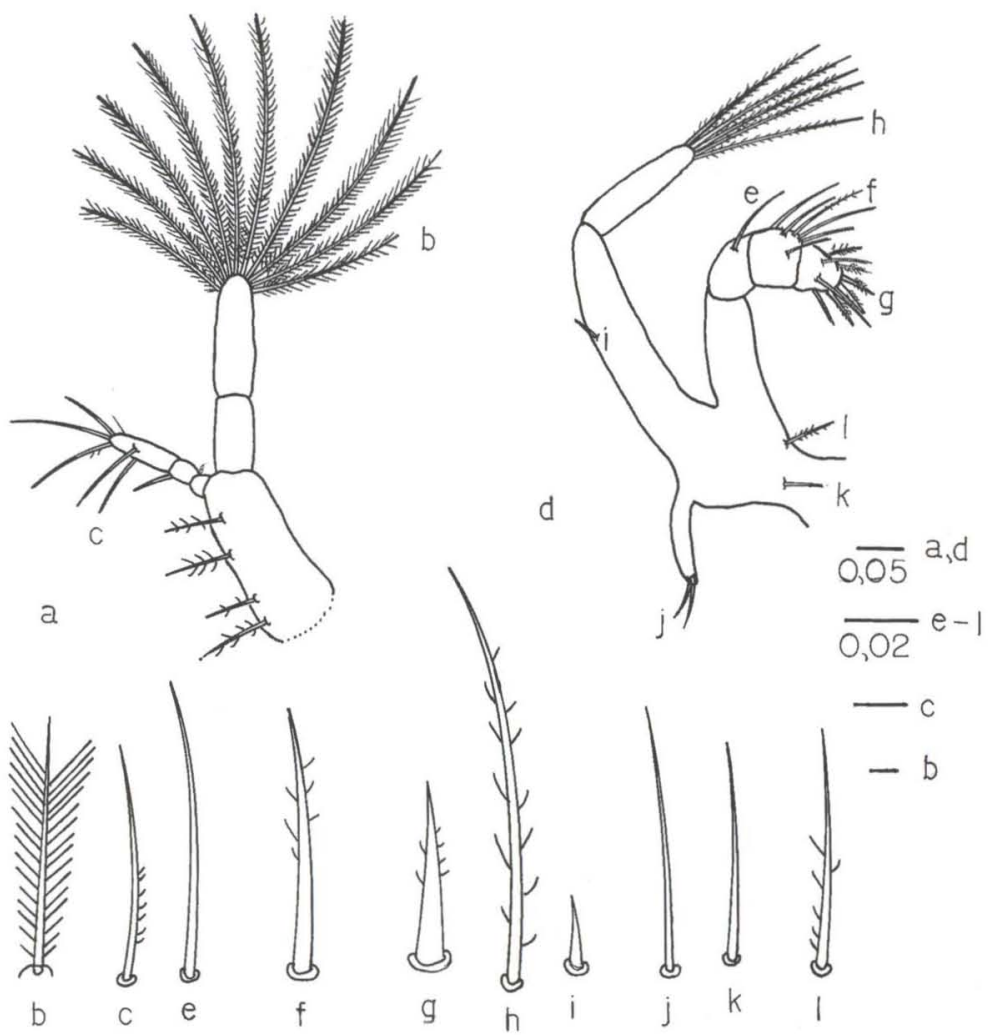

Fig. 16. Chasmagnathus granulata, segundo maxilípodo.(a) ZIV; (b) cerda plumosa exop. ZIV; (c) cerda paposa endop. ZIV; (d) MI, MII; (e) cerda simples endop. MI, MII; (f, g) cerdas paposas endop. MI, MII; (h) cerda paposa exop. MI, MII; (i) cerda simples exop. MI, MII; (j) cerda simples epip. MI, MII; (k) cerda simples protop. MI, MII; (I) cerda paposa protop. MI, MII.

podos, os pleópodos e os urópodos completam a sua morfologia geral. Presença de sete pares de brânquias assim distribuídas: um par de pleurobrânquias no segmento correspondente ao terceiro pereiópodo, um par de pleurobrânquias no segmento corresponde ao segundo pereiópodo, duas pares de artrobrânquias nos quelípodos, um par de artrobrânquias e um par bulbos de podobrânquias nos terceiros maxilípodos e um par de bulbos de podobrânquias nos segundos maxilípodos.

Abdome: (Fig. 3 i) com seis somitos, mais largos que longos. Somitos segundo ao quinto com um par de pleópodos ( $\mathrm{pl} 2, \mathrm{pl} 3, \mathrm{pl} 4, \mathrm{pl} 5)$, respectivamente (Fig. 18 pl2-pl5) e o sexto somito com um par de urópodos (U) (Fig. 18 u). O pl2 e pl3 são bisegmentados e birremes, com, no segmento distal, 12 e 13 cerdas plumosas, respectivamente. $\mathrm{O}$ pl 4 apresenta 16 cerdas plumosas e o pl5 15 cerdas plumosas (Fig. 18 pl2-pl5). Os urópodos são bisegmentados, com uma cerda plumosa no segmento proxima e oito cerdas plumosas no distal (Fig. 18 u, a). O 


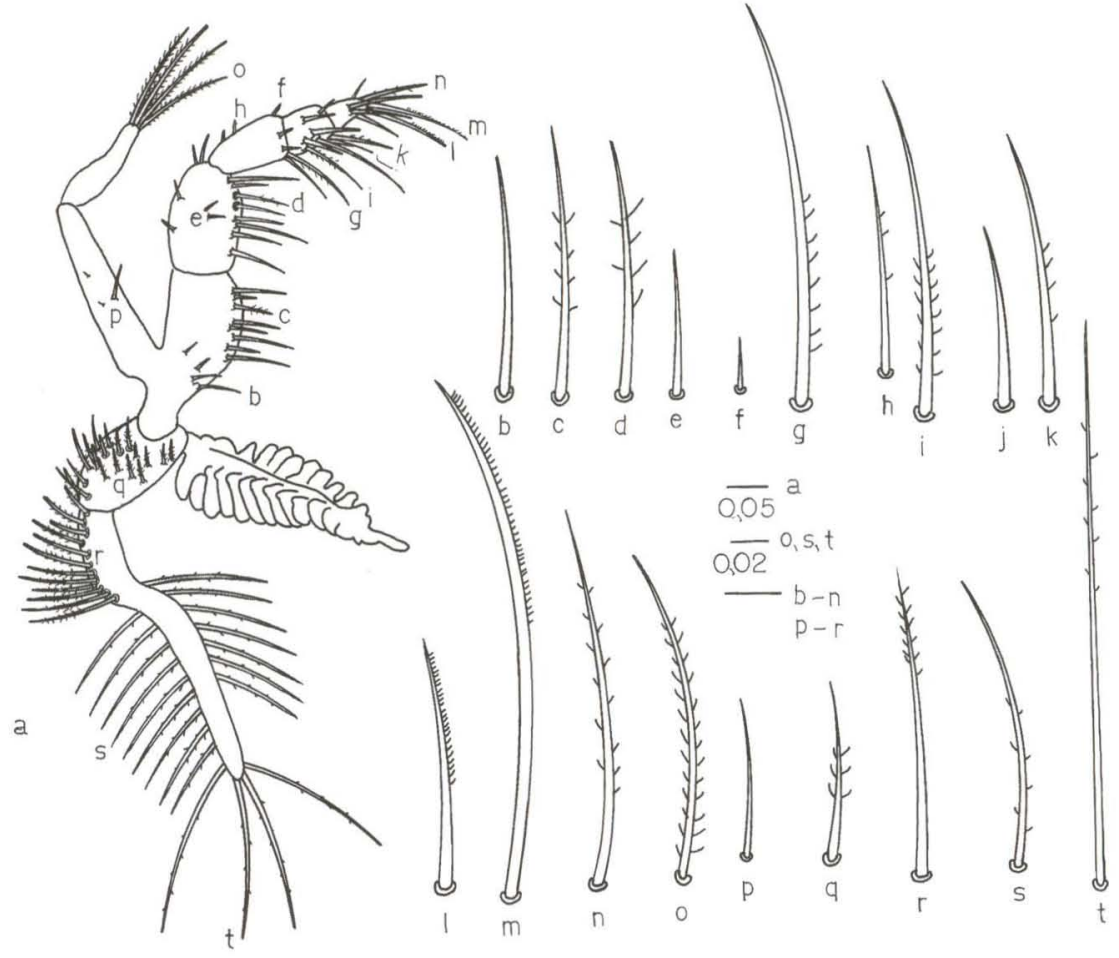

Fig. 17. Chasmagnathus granulata, terceiro maxilípodo. (a) MI, MII; (b-i, k-n) cerdas paposas endop. MI, MII; (e, f, j) cerdas simples endop. MI, MII; (o) cerda paposa exop. MI, MII; (p) cerda simples exop. MI, MII; (q) cerda paposa protopodito MI, MII; (r-t) cerdas paposas epipodito MI, MII.

primeiro segundo e terceiro somitos abdominais possuem as margens póstero-laterais com pequenas projeções dentiformes. Os somitos quarto e quinto possuem dois espinhos póstero-laterais dirigidos para a parte posterior, sendo os do quinto somito maiores que os do quarto. O sexto somito não possui projeções espiniformes nas margens póstero-laterais (Fig. 3 i). O primeiro somito apresenta 11(13) cerdas paposas na região mediana (Fig. 3 j). Os segundo terceiro e sexto somitos apresentam um par de cerdas simples póstero-laterais bem como 3, 4, 1 pares de cerdas simples na sua superfície dorsal, respectivamente (Fig. 3 i). O quarto e quinto somitos possuem, respectivamente, cinco e quatro pares de cerdas simples na superfície dorsal (Fig. 3 i, k). O telso possui forma subretangular com a margem posterior convexa possuindo na sua extremidade quatro cerdas plumosas (Fig. $3 \mathrm{~m}$ ) e quatro pares de cerdas simples na superfície dorsal.

Antênula (Fig. 4 j): segmento basal bem desenvolvido com três cerdas simples e duas cerdas paposas na sua superfície (Fig. 4 k, l). primeiro segmento do pedúnculo com três cerdas simples distais no segmento proximal. Endopodito reduzido, não segmentado com duas cerdas simples distais (Fig. 4 n). Flagelo com três estetos no primeiro segmento, três no segundo e dois estetos e duas cerdas simples no terceiro (Fig. 4 j, m). 

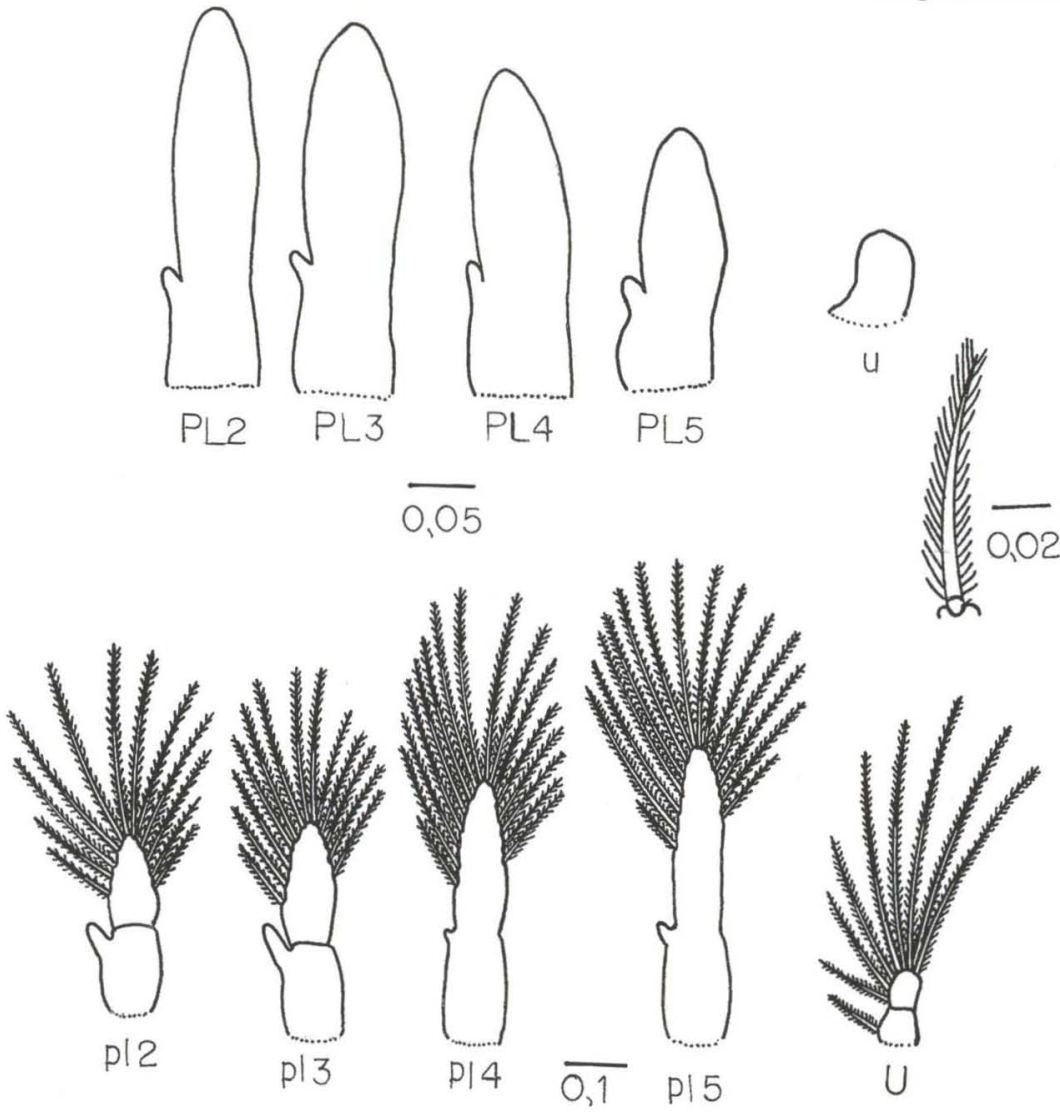

pl3

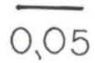

Fig. 18. Chasmagnathus granulata, pleópodos: (PL2-PL5) segundo ao quinto pares de pleópodos ZIV; (u) urópodo ZIV: (pl2, pl3, pl4, pl5) segundo ao quinto pares de pleópodos $\mathrm{MI}$, MII; (a) cerda plumosa pleópodos MI, MII; (U) urópodo MI, MII.

Antena (Fig. 5 t): pedúnculo constituído por três segmentos com o segundo e terceiro providos de 2(3) e 3(4) cerdas simples, respectivamente (Fig. 5 t). Flagelo antenal composto por oito segmentos, respectivamente, do proximal para o distal: primeiro segmento: duas cerdas simples, segundo e terceiro lisos, quarto com três cerdas simples; quinto com uma cerda paposa (Fig. 5 x), sexto com quatro cerdas simples; sétimo com uma cerda paposas e duas simples (Fig. 5 y); oitavo com duas cerdas simples (Fig. $5 \mathrm{z}$ ).

Mandíbula (Fig. 6 e): constituída por uma lâmina cortante bem quitinizada com as margens simples. Palpo bisegmentado com três cerdas simples e cinco paposas (Fig. $6 \mathrm{f}-\mathrm{i}$ ).

Maxílula (Fig. 9 a): endito coxal com 15(17) cerdas paposas (Fig. 9 b-j). Endito basal com 20(22) cerdas paposas (Fig. 9 k-m, q-s) e duas cuspidadas (Fig. 9 $\mathrm{n}, \mathrm{p})$. Endopodito bisegmentado com duas cerdas simples distais e duas cerdas simples proximais no segmento distal (Fig. $9 \mathrm{u}-\mathrm{x}$ ) e duas cerdas simples no segmento proximal, sendo uma subdistal e uma proximal (Fig. 9 t, y). 

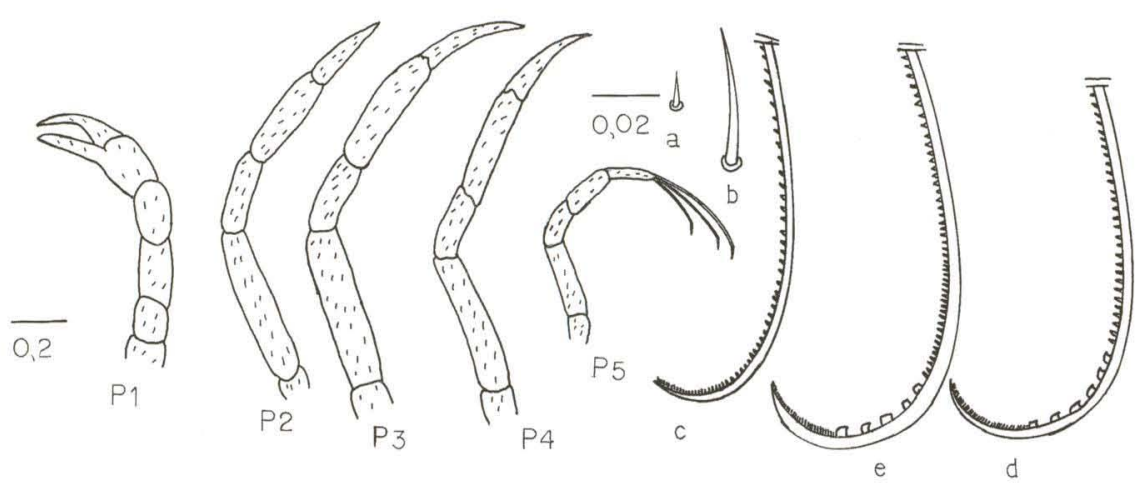

Fig. 19. Chasmagnathus granulata. (P1-P5) Primeito ao quinto pares de pereiópodos MI, MII; (a-b) cerdas simples dos pereiópodos MI, MII; (c-e) cerdas unciformes do quinto par de pereiópodos $\mathrm{MI}$, MII.

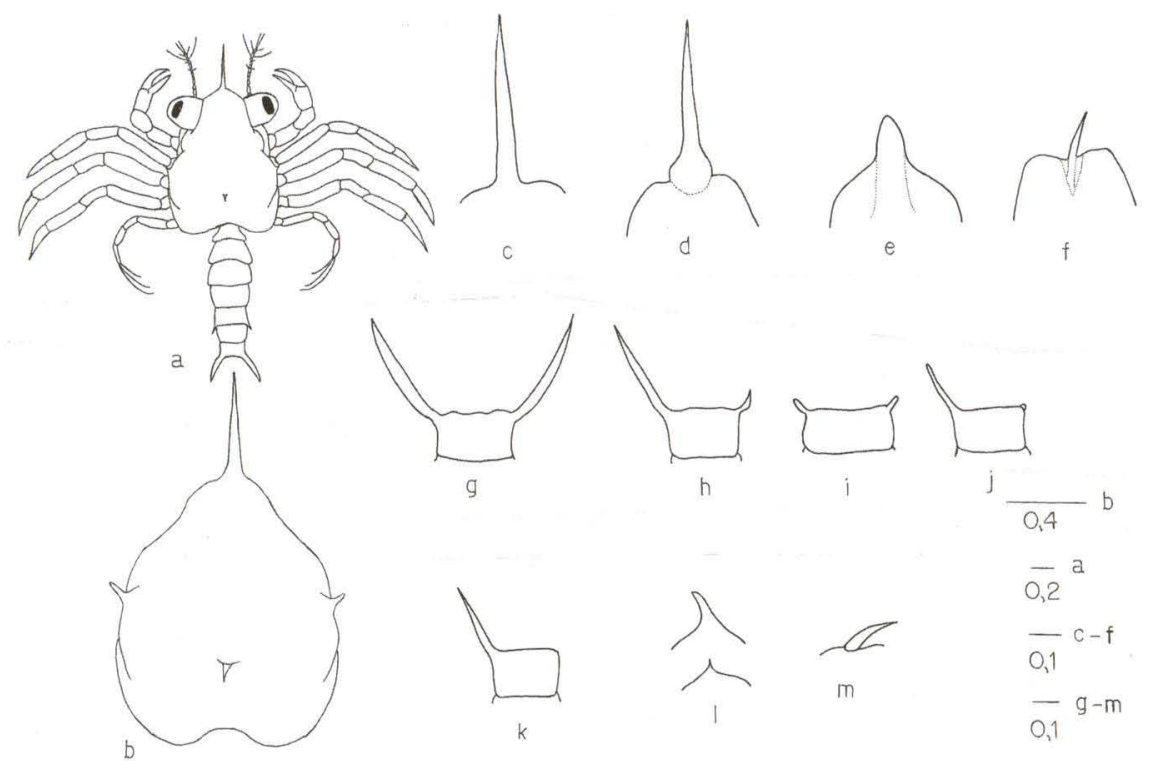

Fig. 20. Chasmagnathus granulata. (a) Megalopa II; (b) carapaça megalopa II; (c-f) tipos de espinho rostral R1, R2, R3, R4; (g-k) tipos de telso T1 a T5; (I) tipos de espinho lateral; (m) tipo de espinho dorsal, vista lateral.

Maxila (Fig. 11 p): endito coxal com uma cerda simples e 15 paposas no lóbulo proximal; e cinco cerdas paposas no lóbulo distal (Fig. 11 q-s). Endito basal com uma cerda paposa e seis simples no lóbulo proximal, (Fig. $11 \mathrm{~s}$ ); 12(14) cerdas simples no lóbulo distal. Exopodito (escafognatito) com 48(52) cerdas plumosas marginais (Fig. 11 p, t). Endopodito desprovido de cerdas. 
Primeiro maxilípodo (Fig. 14 a): endito coxal com 15(16) cerdas, sendo uma paposa e as demais simples. (Fig. 14 c, d). Endito basal com 15(16) cerdas, sendo uma simples e as demais paposas (Fig. 14 e, f). Endopodito não segmentado com duas cerdas simples na extremidade (Fig. 14 g). Exopodito bisegmentado com 2(1) cerdas paposas no segmento proximal (Fig. 14 i, j) e 4(5) paposas no distal (Fig. 14 a, h). Epipodito com seis cerdas simples (Fig. 14 a, k).

Segundo maxilípodo (Fig. 16 d): protopodito com uma cerda simples e uma cerda paposa proximais (Fig. 16 k, l). Endopodito tetrasegmentado com, respectivamente, $0,1,6(7), 8(10)$ cerdas, do segmento proximal para o distal. O segundo segmento com uma cerda simples e os demais com cerdas paposas (Fig. $16 \mathrm{~d}$-g). Exopodito bisegmentado, com uma cerda simples no segmento proximal (Fig. 16 i) e com 5(4) cerdas paposas no distal (Fig. 16d, h). Epipodito com duas cerdas simples distais (Fig. 16 d, j).

Terceiro maxilípodo (Fig. 17 a): protopodito com 20(18) cerdas paposas (Fig. 17 q). Endopodito pentasegmentado com, respectivamente, 13(10), 14(16), $7(9), 8(6), 6(5)$ cerdas do segmento proximal para o distal; primeiro segmento: uma cerda paposa e as demais simples (Fig. 17 b, c); segundo segmento: uma cerda simples e demais paposas; terceiro segmento: uma cerda simples e as demais paposas (Fig. 17 f-h), quarto segmento: uma cerda simples e as demais paposas (Fig. $17 \mathrm{i}$, j); quinto segmento: duas cerdas paposas e as demais simples (Fig. $17 \mathrm{k}-\mathrm{n}$ ). Exopodito bisegmentado com 3(4) cerdas simples na porção mediana do segmento proximal (Fig. 17 p) e 4(3)cerdas paposas no segmento distal (Fig. 17 o). Epipodito com 13(12) cerdas paposas na porção distal, 16(18) cerdas simples na porção mediana e 4(3) longas cerdas paposas na porção distal (Fig. 17 r-t).

Pereiópodos (Fig. 19 pl-p5): quelípodos simétricos com os segmentos providos de pequenas cerdas simples (Fig. 19 pl, a, b). O quinto pereiópodo apresenta, três longas cerdas unciformes na região distal do dáctilo (Fig. 19 p5, c-e). Os segundo, terceiro, quarto e quinto pereiópodos são recobertos por pequenas cerdas simples (Fig. 19 p2-p5).

\section{Megalopa II (Fig. 20)}

Carapaça: (Fig. 20 a, b) subquadrangular, dorsalmente convexa com comprimento um pouco maior do que a largura. Na região dorsal apresenta minúsculas cerdas simples esparsas e, nas regiões póstero-laterais e posterior, 80 pequenas cerdas paposas, dispostas regularmente nas margens. Apresenta ainda, um par de espinhos laterais ocupando a posição latero-medial da carapaça ocorrendo de quatro formas distintas: um par de espinhos longos, um par de espinhos curtos, um par de espinhos sendo o direito longo e o esquerdo curto e um par de espinhos sendo o esquerdo longo e o direito curto (Fig. 20 b, 1). A superfície mediana da carapaça apresenta um curto espinho dorsal (Fig. 20 b, m). O rostro apresenta-se como uma estrutura anômala com quatro tipos distintos de espinho rostral: (R1) espinho rostral que projeta-se diretamente da superfície do rostro, (R2) espinho rostral que se projeta de uma invaginação do rostro, (R3) espinho rostral que se projeta de uma evaginação da superfície ântero-dorsal do rostro, (R4) espinho que se projeta de uma invaginação ântero-ventral do rostro (Fig. 20 c-f). Os olhos são pedunculados (Fig. 20a). 

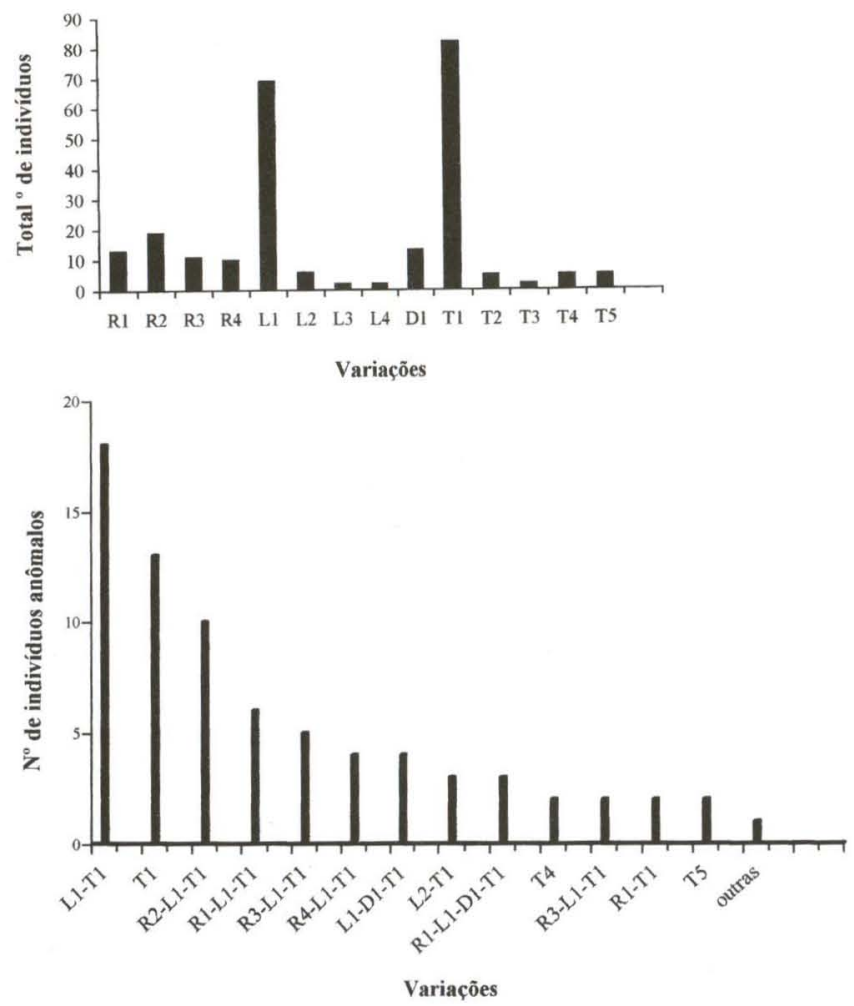

Figs 21-22. Chasmagnathus granulata, fase de megalopa II. (21) Freqüência das variações morfológicas; (22) combinações de variações morfológicas.

Abdome (Fig. 20 a): presença de seis somitos, mais largos do que longos, com os somitos segundo ao quinto providos de um par de pleópodos (p12-p15), e o sexto com um par de urópodos (U) (Fig. 18 pl2-pl5, u). O pl2 e pl3 são bisegmentados e birremes, possuindo no segmento distal 12 e 13 cerdas plumosas, respectivamente. O pl4 apresenta 16 cerdas plumosas e o pl5 15 cerdas plumosas (Fig. 18 pl2-pl5). Os urópodos são bisegmentados, com duas cerdas plumosas no segmento proximal e nove no distal (Fig. $18 \mathrm{u}$ ). O primeiro segundo e terceiro somitos possuem as margens póstero-laterais com pequenas projeções dentiformes. O quinto somito possui dois espinhos póstero-laterais dirigidos para a região posterior. O sexto somito não possui projeções espiniformes nas margens póstero-laterais (Fig. 20 a). O primeiro somito apresenta 15(13) cerdas paposas na região mediana, os segundo terceiro e sexto somitos apresentam um par de cerdas simples póstero-laterais bem como 4, 4, 2 pares de cerdas simples na sua superfície dorsal, respectivamente. O quarto e quinto somitos possuem, respectivamente, seis e cinco pares de cerdas simples na sua superfície dorsal (Fig. 3 i). O telso apresenta-se como uma estrutura anômala assumindo cinco formas distintas: (T1) telso com dois longos ramos na furca, (T2) telso com um ramo 
longo e o outro curto, (T3) telso com os dois ramos da furca curtos, (T4) com um ramo longo e o outro apresentando-se como um pequeno bulbo, (T5) telso com apenas um ramo longo na furca. $\mathrm{O}$ telso possui ainda quatro pares de cerdas simples na superfície dorsal (Fig. 20 a, g-k).

Antênula (Fig. 4 j): segmento basal bem desenvolvido com três cerdas simples e três paposas na sua superfície; primeiro segmento do pedúnculo com quatro cerdas simples distais no segmento proximal. Endopodito reduzido, não segmentado com três cerdas simples distais (Fig. 4 n). Flagelo com três estetos no primeiro segmento, três no segundo e dois estetos e duas cerdas simples no terceiro (Fig. 4 m).

Antena (Fig. 5 t): pedúnculo constituído por três segmentos com o segundo e terceiro providos de 3(2) e 3(4) cerdas simples, respectivamente. Flagelo antenal composto por oito segmentos com respectivamente, a seguinte distribuição de cerdas do proximal para o distal: primeiro segmento: três cerdas simples, terceiro segmento: três cerdas simples; quarto segmento: três cerdas simples, quinto segmento: uma cerda paposa, sexto segmento: cinco cerdas paposas; sétimo segmento: três cerdas paposas; oitavo segmento: duas cerdas simples (Fig. $5 \mathrm{t}-\mathrm{z}$ ).

Mandíbula (Fig. 6 e): constituída por uma lâmina cortante bem quitinizada com as margens lisas. Palpo bisegmentado com oito cerdas, sendo três simples e as demais paposas (Fig. $6 \mathrm{e}, \mathrm{m}$ ).

Maxílula (Fig. 9 a): endito coxal com 16(18) cerdas paposas (Fig. 9 b-j). Endito basal com 22(23) cerdas paposas (Fig. 9 k, 1, g-s) e três cuspidadas (Fig. 9 $\mathrm{m}, \mathrm{p})$. Endopodito bisegmentado com três cerdas simples distais e três cerdas lisas proximais no segmento distal e duas cerdas simples no segmento proximal, sendo uma subdistal e uma proximal (Fig. $9 \mathrm{t}-\mathrm{x}$ ).

Maxila (Fig. 11 p): endito coxal com 17 cerdas no lóbulo proximal, sendo uma cerda simples e as demais paposas (Fig. 11q); seis cerdas paposas no lóbulo distal (Fig. 11 r). Endito basal com oito cerdas no lóbulo proximal, sendo uma cerda paposa e as demais simples, e 12(14) cerdas simples no lóbulo distal (Fig. $11 \mathrm{~s}$ ). Exopodito (escafognatito) com 48(52) cerdas plumosas marginais. Presença de endopodito desprovido de cerdas (Fig. $11 \mathrm{p}, \mathrm{t}$ ).

Primeiro maxilípodo (Fig. 14 a): endito coxal com 17(18) cerdas, sendo uma cerda paposa e as demais simples (Fig. 14 b). Endito basal com 15(16) cerdas, sendo uma cerda simples e as demais paposas (Fig. 14 e, f). Endopodito não segmentado com duas cerdas simples na extremidade (Fig. 14 g). Exopodito bisegmentado com 3(2) cerdas paposas no segmento proximal e 4(5) cerdas paposas no distal (Fig. 14 h-j). Epipodito com sete cerdas simples (Fig. 14 k).

Segundo maxilípodo (Fig. 16 d): protopodito com três cerdas paposas proximais (Fig. 161). Endopodito tetrasegmentado com, respectivamente, 0, 1, 6(7), 8 (10) cerdas, do segmento proximal para o distal. O segundo segmento com uma cerda simples e o terceiro e quarto segmentos com todas as cerdas paposas (Fig. 16 e-g). Exopodito bisegmentado, com duas cerdas simples no segmento proximal e 6(5) cerdas paposas no distal (Fig. $16 \mathrm{~h}$ ). Epipodito com duas cerdas simples na porção distal (Fig. 16 j). 
Terceiro maxilípodo (Fig. 17 a): protopodito com 22(20) cerdas paposas (Fig. 17 k). Endopodito pentasegmentado com, respectivamente, 13(10), 14(16), $7(9), 8(6), 6(5)$ cerdas do segmento proximal para o distal; primeiro segmento: uma cerda paposa e as demais simples; segundo segmento: uma cerda simples e demais paposas; terceiro e quarto segmentos: uma cerda simples e as demais paposas, quinto segmento: quatro cerdas paposas e as demais simples (Fig. 17 b-n). Exopodito bisegmentado com 4(3) cerdas simples na porção mediana do segmento proximal e 5(4) cerdas paposas no segmento distal (Fig. 17 p). Epipodito com 15(16) cerdas paposas na porção distal, 17(15) cerdas simples na porção medial e 5(4) longas cerdas paposas na porção distal (Fig. $17 \mathrm{r}-\mathrm{t}$ ).

Pereiópodos (Fig. 19 p1-p5): quelípodos simétricos com os segmentos providos de pequenas cerdas simples (Fig. 19 p1-p5). O quinto pereiópodo apresenta, três longas cerdas unciformes na região distal do dáctilo. Os segundo, terceiro, quarto e quinto pereiópodos são recobertos por pequenas cerdas simples (Fig. 19 p1-p5, a-e).

\section{DISCUSSÃO E CONCLUSÕES}

A busca de novas alternativas científicas que auxiliem na compreensão dos fenômenos biológicos tem sido uma constante nas atividades que se referem aos aspectos morfo-taxonômicos dos crustáceos decápodos, especificamente, sob o ponto de vista do desenvolvimento pós-embrionário, procurando auxiliar na elucidação dos aspectos sistemáticos inerentes a este grupo. Sob este prisma, o estudo das cerdas, que ainda encontra-se nos seus primórdios, tem demonstrado ser uma importante ferramenta para a identificação e determinação das formas larvais planctônicas.

No que se refere à morfologia e classificação das cerdas de crustáceos decápodos, POHLE \& Telford (1981) identificaram 32 tipos em Dissodactylus crinitichelis Moreira, 1901 (Brachyura: Pinnotheridae). Já INGLE (1992) estudando os Brachyura do Alântico NE identificou tipos de cerdas semelhantes, estruturalmente, aos descritos por POHLE \& TELFORD (1981). A manutenção de estruturas como, por exemplo, as cerdulas durante o processo de metamorfose não é uma constante para todos os tipos de cerdas. Com relação ao número e tipos de cerdas CALAZANS \& INGLE (1998) estudando a morfologia de cerdas nos estágios larvais de Pleoticus muelleri Bate, 1888 (Decapoda: Solenoceridae) encontraram mais de 60 tipos. POHLE \& Telford (1981) descrevem também algumas mudanças como nas cerdas cuspidadas multidenticuladas e plumodenticuladas, que gradualmente vão perdendo todas as suas cerdulas durante as mudas subsequentes até permanecerem somente dentículos, na haste, na fase de megalopa ou primeiro estágio juvenil. BoOKHout \& Costlow (1974) observaram o mesmo em Portunus spinicarpus (Stimpson, 1871) com relação às cerdas cuspidadas plumodenticuladas. Para Chasmagnathus granulata observou-se processo semelhante com relação às cerdas plumosas no exopodito da maxila as quais, quando da passagem para a fase juvenil transformam-se em cerdas paposas. Observou-se durante os estágios da fase de zoea e megalopa, um aumento do número e predomínio do tipo de cerda denominada paposa principalmente no lobo proximal dos enditos coxal e basal da maxila. Os 
estudos comparativos com o trabalho realizado por BosCHI et al. (1967) no que se refere aos tipos, posição e freqüência das cerdas, enfatizam e ampliam a compreensão destes caracteres morfológicos, cujos resultados encontram-se na tabela V.

Com relação ao número de estágios na fase de megalopa, WEAR (1967) ao descrever o desenvolvimento embrionário e pós-embrionário de Pilumnus novaezealandiae Filhol, 1886 e $P$. lumpinus Bennett, 1964, afirma que "muito raramente ocorre a presença de dois ou mais estágios na fase de megalopa. Em seu trabalho, realiza uma revisão na literatura na qual são apresentadas as seguintes citações: BIRGE (1882) descreve quatro estágios na fase de megalopa para a espécie Neopanope texana; CANO (1891) descreve dois estágios na fase de megalopa para as espécies Pilumnus hirtellus, P. villosus e P. spinifer; HyMAN (1924) descreve dois estágios de megalopa em Pachygrapsus marmoratus; HYMAN (1925) descreve dois estágios na fase de megalopa para as espécies Neopanope texana, Xanthus rivolus, X. floridus e X. tuberculatus; HaLe (1931) descreve $P$. vestitus no qual cita um estágio de megalopa com pleópodos sem cerdas e portanto sem função natatória, estes surgindo no primeiro estágio juvenil; AIKAWA (1937) descreve dois estágios de megalopa para as espécies Charybdis bimaculata e Plagusia dentipes; WEAR (1967) descreve para Plagusia capensis dois estágios na fase de megalopa e afirma que em $P$. vestitus, descrito por Hale (1931), o primeiro estágio juvenil corresponde a um segundo estágio da fase de megalopa".

A procura da uniformização na utilização de termos propostos pelos diferentes autores quando em outros idiomas tem levado a uma grande dificuldade no que concerne à tradução e adaptação dos mesmos ànossa realidade cientifica.

Fato curioso ocorre com relação à fase de megalopa em Chasmagnathus granulata. Foram obtidos, no mesmo estágio, diversos padrões morfológicos cujas variações, combinações e freqüências encontram-se citadas nas tabelas II-III e figuras 20-22.

A presença de 102 megalopas $(97,14 \%)$ com padrões morfológicos diferenciados, conforme figuras e tabelas citadas anteriormente, acarreta, inicialmente um questionamento sobre o padrão corporal típico da fase de megalopa descrito por BosCHI et al. (1967), o qual neste cultivo foi encontrado em somente três indivíduos $(2,86 \%)$. Foram realizados posteriormente, mais quatro cultivos maciços, nas mesmas condições experimentais, utilizando-se quatro fêmeas ovígeras diferentes, obtendo-se no total 35 megalopas, sendo que, em todos eles, não foram mais obtidos os diferentes padrões acima citados, embora o " $n$ " nos quatro cultivos, tenha sido proporcionalmente bem menor (Figs 20-22).

Essas variações no plano corporal podem ser caracterizadas como estruturas anômalas uma vez que fogem ao conceito do plano corporal característico da fase de megalopa conforme descrito por LEBOUR (1928): "a fase de megalopa caracteriza-se pela presença de pleópodos desenvolvidos com longas cerdas, abdome curvado horizontalmente, maxilípodos funcionando como peças bucais. O corpo é achatado dorso-ventralmente, terceiro maxilípodo bastante desenvolvido e todos os pereiópodos assemelham-se à forma adulta. Forma semelhante ao adulto exceto pelo fato do abdome não ser normalmente curvado sob o cefalotórax". Desta forma, se 
Tabela V. Chasmaganthus granulata. Análise das diferenças morfológicas nas fases de zoea e megalopa I do presente trabalho e BoscH et al. (1967).

\begin{tabular}{|c|c|c|c|c|c|}
\hline Estágios & Referência & $\begin{array}{l}\text { Carapaça } \\
\text { (BA) bordo anterior } \\
\text { (BP) bordo posterior } \\
\text { (C) cerdas } \\
\text { (C) comprimento carapaça } \\
\text { (CL) cerda lisa } \\
\text { (CPL) cerda plumosa } \\
\text { (E) estetos } \\
\text { (ER) espinho rostral } \\
\text { (ES) espinhos } \\
\text { (MPL) margem póstero-lateral } \\
\text { (POR) região proximal das órbitas } \\
\text { (RD) região póstero-dorsal } \\
\text { (RP) região póstero-ventral } \\
\text { (TD) tamanho espinho dorsal }\end{array}$ & $\begin{array}{l}\text { Antênula } \\
\text { (1S) } 1^{\circ} \text { segmento exopodito } \\
\text { (2S) } 2^{\circ} \text { segmento exopodito } \\
\text { (3S) } 3^{\circ} \text { segmento exopodito } \\
\text { (C) cerdas } \\
\text { (CL) cerda lisa } \\
\text { (CPL) cerda plumosa } \\
\text { (E) esteto } \\
\text { (E) estetos } \\
\text { (EB) endito basal } \\
\text { (EC) endito coxal } \\
\text { (EN) endopodito } \\
\text { (ER) endopodito rudimentar } \\
\text { (ES) espinhos } \\
\text { (EX) exopodito } \\
\text { (FL) flagelo }\end{array}$ & $\begin{array}{l}\text { Antena } \\
\text { (2S) } 2^{\circ} \text { segmento do pedúnculo } \\
\text { (3S) } 3^{\circ} \text { segmento do pedúnculo } \\
\text { (C) cerdas } \\
\text { (CL) cerda lisa } \\
\text { (CPL) cerda plumosa } \\
\text { (EN) endopodito } \\
\text { (ES) espinhos } \\
\text { (F) fileira } \\
\text { (FEP) face externa protopodito } \\
\text { (FIP) face interna protopodito } \\
\text { (FL) flagelo } \\
\text { (PE) processo espinhoso protopodito } \\
\text { (PR) protopodito }\end{array}$ & $\begin{array}{l}\quad \text { Mandibula } \\
\text { (C) cerdas } \\
\text { (CL) cerda lisa } \\
\text { (CPL) cerda plumosa } \\
\text { (D) projeção dentiforme } \\
\text { (E) estetos } \\
\text { (ES) espinhos } \\
\text { (PA) palpo mandibular } \\
\text { (PI) processo incisivo } \\
\text { (SC) superficie cortante }\end{array}$ \\
\hline Zoea I & $\begin{array}{l}\text { Boschi et al. (1967) } \\
\text { Presente trabalho }\end{array}$ & $\begin{array}{l}\text { C- }-0,37 \mathrm{~mm} \\
\text { C- } 0,42 \mathrm{~mm}\end{array}$ & $\begin{array}{l}3 \mathrm{E}, 1 \mathrm{CL} \\
2 \mathrm{E}, 1 \mathrm{CL}\end{array}$ & $\begin{array}{c}P E-E S \\
F I P-2 F-13 E S \\
F E P-2 F-9 E S\end{array}$ & $\begin{array}{c}S C-5 A 6 D \\
P I-7 D\end{array}$ \\
\hline Zoea II & $\begin{array}{l}\text { Boschi et al. (1967) } \\
\text { Presente trabalho }\end{array}$ & $\begin{array}{c}\text { C }-0,53 \mathrm{~mm} \\
\text { C }-0,51 \mathrm{~mm} \\
\text { TD }-2 / 3 \text { do tamanho do ER }\end{array}$ & $\begin{array}{c}1 \mathrm{CPL} \\
3 \mathrm{E}, \mathrm{ICL}\end{array}$ & $\begin{array}{l}\text { FIP }-\overline{12} \text { ES } \\
\text { FEP }-15 \text { ES }\end{array}$ & $\mathrm{PI}-\overline{10 D}$ \\
\hline Zoea III & $\begin{array}{l}\text { Boschi et al. (1967) } \\
\text { Presente trabalho }\end{array}$ & $\begin{array}{c}\text { TD - longo e curvado para trás } \\
\text { BP - } 3,4 \mathrm{C} \\
\text { TD - 2/3 do tamanho do ER } \\
\text { BP - } 8 \mathrm{CPL}\end{array}$ & $\begin{array}{l}3 \mathrm{E} \\
3 \mathrm{CL} \\
4 \mathrm{E} \\
1 \mathrm{CL}\end{array}$ & $\begin{array}{c}- \\
\text { FIP - } 16 \text { ES } \\
\text { FEP - } 19 \text { ES }\end{array}$ & $\begin{array}{l}\text { SC - dentes bem } \\
\text { pronunciados } \\
\text { PI-9D }\end{array}$ \\
\hline Zoea IV & $\begin{array}{l}\text { Boschi et al. (1967) } \\
\text { Presente trabalho }\end{array}$ & $\begin{array}{c}\text { C - } 0,94 \mathrm{~mm} \\
\mathrm{BA}-3 \mathrm{C} \\
\mathrm{C}-0,97 \mathrm{~mm} \\
\mathrm{RP}-14 \mathrm{CPL} \\
3 \mathrm{CPL} \text { - abaixo do ângulo interno do espinho } \\
\text { dorsal com a carapaça }\end{array}$ & $\begin{array}{c}3 \mathrm{E} \\
3 \mathrm{CL} \\
\mathrm{ER}, 8 \mathrm{E}\end{array}$ & - & $\begin{array}{c}- \\
P I-13 D\end{array}$ \\
\hline MegalopaE & aBoschi et al. (1967) & $\begin{array}{c}\mathrm{C}-1,2 \mathrm{~mm} \\
\mathrm{C}-1,07 \mathrm{~mm} \\
\mathrm{MPL}-70 \mathrm{CPL} \\
\text { POR - } 3 \text { pares CPL dorsais }\end{array}$ & $\begin{array}{c}\text { FL - 3E e outro de menor tamanho com } \\
\text { estetos } \\
\text { EC - } 3 \mathrm{CL}, 2 \mathrm{CPL} \\
\mathrm{EB}-3 \mathrm{CL} \\
\mathrm{EN}-2 \mathrm{CL} \\
\mathrm{EX}-\text { trissegmentado } \\
1 \mathrm{~S}-3 \mathrm{E}, 2 \mathrm{~S}-3 \mathrm{E} \\
3 \mathrm{~S}-2 \mathrm{E}, 2 \mathrm{CL}\end{array}$ & $\begin{array}{c}2 \mathrm{~S}-2 \mathrm{CL} \\
3 \mathrm{~S}-3 \mathrm{CL} \\
\mathrm{FL}-7 \mathrm{CL}, 8 \mathrm{CPL} \text {, com oito } \\
\text { segmentos }\end{array}$ & $\frac{-}{P A-3 C L, 5 C P L}$ \\
\hline
\end{tabular}


Tabela V. Continuação.

\begin{tabular}{|c|c|c|c|c|c|}
\hline Estágios & Referência & $\begin{array}{l}\text { Maxílula } \\
\text { (C) cerdas } \\
\text { (CL) cerda lisa } \\
\text { (CPL) cerda plumosa } \\
\text { (E) estetos } \\
\text { (EB) endito basal } \\
\text { (EC) endito coxal } \\
\text { (EN) endopodito } \\
\text { (ES) espinhos } \\
\text { (FEL) face lateral externa } \\
\text { (MCT) microtríquias } \\
\text { (PR) Protopodito }\end{array}$ & $\begin{array}{l}\text { Maxila } \\
\text { (BA) Bordo anterior, (C) cerdas } \\
\text { (CL) cerda lisa, (CPL) cerda plumosa } \\
\text { (E) estetos, (EB) endito basal } \\
\text { (EC) endito coxal, (EN) endopodito } \\
\text { (EP) extremidade posterior } \\
\text { (ES) espinhos, (EX) exopodito } \\
\text { (FL) face lateral, (FM) face mesial } \\
\text { (LDB) lobo distal endito basal } \\
\text { (LDC) lobo distal endito coxal } \\
\text { (LPB) lobo proximal endito basal } \\
\text { (LPC) lobo proximal endito coxal } \\
\text { (M) margem, (MCT) microtríquias } \\
\text { (MPA) microtríquias da porção } \\
\text { terminal afilada, (SL) superficie lateral }\end{array}$ & $\begin{array}{l}1^{\circ} \text { Maxilípodo } \\
\text { (1S) } 1^{2} \text { segmento do endopodito } \\
\text { (2S) } 2^{\circ} \text { segmento do endopodito } \\
\text { (3S) } 3^{\circ} \text { segmento do endopodito } \\
\text { (5S) } 5^{\circ} \text { segmento do endopodito } \\
\text { (AR) arranjo das cerdas } \\
\text { (C) cerdas, (CL) cerda lisa } \\
\text { (CPL) cerda plumosa, (E) estetos } \\
\text { (EB) endito basal, (EC) endito coxal } \\
\text { (EN) endopodito, (ES) espinhos } \\
\text { (EX) exopodito } \\
\text { (MI) margem interna }\end{array}$ & $\begin{array}{l}\quad 2^{\circ} \text { Maxilipodo } \\
\text { (1S) } 1^{\circ} \text { segmento endopodito } \\
\text { (3S) } 3^{\circ} \text { segmento endopodito } \\
\text { (C) cerdas } \\
\text { (CE) cerda espinhosa } \\
\text { (CL) cerda lisa } \\
\text { (CPL) cerda plumosa } \\
\text { (E) estetos } \\
\text { (EB) endito basal } \\
\text { (EN) endopodito } \\
\text { (EPI) epipodito } \\
\text { (ES) espinhos } \\
\text { (EX) exopodito } \\
\text { (PR) protopodito }\end{array}$ \\
\hline \multirow[t]{2}{*}{ Zoea I } & Boschi et al. (1967) & EC - $4 C, E B-7$ ou $8 C$ & - & $E B-7 C, E N-1 C$ & $1 \mathrm{~S}-1 \mathrm{C}$ \\
\hline & Presente trabalho & $\begin{array}{c}\mathrm{EC}-1 \mathrm{CL}, 4 \mathrm{CPL}, \mathrm{EB}-1 \mathrm{CL}, 4 \mathrm{CPL} \\
\mathrm{PR}-\mathrm{FEL}-\mathrm{MCT}\end{array}$ & MPA & $\begin{array}{l}E B-2 C P L, 8 C L \\
E N-1 S-2 C P L\end{array}$ & $3 S-1 C P L, 5 C L$ \\
\hline Zoea II & $\begin{array}{l}\text { Boschi et al. (1967) } \\
\text { Presente trabalho }\end{array}$ & $\begin{array}{c}E C-5 C P L \\
E C-1 C L, 4 C P L\end{array}$ & $\begin{array}{c}- \\
\text { EC - 4CL, 3CPL, SL - MCT } \\
\text { EB - MCT - SL, EN - MCT - SL } \\
\text { EX - MCT - porçāo proximal e distal }\end{array}$ & $\begin{array}{c}\text { EBMI - 7C } \\
\text { EN - S1 - 1C, S2 - 1C, S5 - } 4 \\
\text { EB MI - 4 CPL, 6CL - AR - 3:3:3:3 } \\
\text { S1 - 2CL. } \\
\text { S2 - 1CL, } 1 \mathrm{CPL}, 5 \mathrm{~S}-3 \mathrm{CL}, 2 \mathrm{CPL}\end{array}$ & $\begin{array}{c}\text { EN - } 3 \text { segmentos, várias } \\
\text { cerdas lisas } \\
\text { EN - } 3 \text { segmentos, } 6 \mathrm{CL}\end{array}$ \\
\hline Zoea III & $\begin{array}{l}\text { Boschi et al. (1967) } \\
\text { Presente trabalho }\end{array}$ & $\begin{array}{c}E C-5 C P L, E B-10 \mathrm{CPL} \\
E C-1 \mathrm{CL}, 5 \mathrm{CPL} \\
\text { EB - 1CL, 9CPL }\end{array}$ & $\begin{array}{l}\text { EX - EP - } 5 \text { Cm EX - BA - 7C } \\
\text { MCT - face lateral e mesial } \\
\text { EX - } 15 \text { CPL marginais } \\
\text { PT - EX - MCT }\end{array}$ & $\begin{array}{c}1 \mathrm{~S}-4 \mathrm{C}, 2 \mathrm{~S}-2 \mathrm{C}, 3 \mathrm{~S}-1 \mathrm{C}, 4 \mathrm{~S}-1 \mathrm{C} \\
5 \mathrm{~S}-1 \mathrm{C} \\
1 \mathrm{~S}-5 \mathrm{CPL}, 2 \mathrm{~S}-1 \mathrm{CL}, 1 \mathrm{CPL}, 3 \mathrm{~S}-1 \mathrm{CL}, \\
1 \mathrm{CPL}, 4 \mathrm{~S}-1 \mathrm{CL}, 1 \mathrm{CPL} \\
5 \mathrm{~S}-1 \mathrm{CL}, 1 \mathrm{CPL}\end{array}$ & $\begin{array}{c}\text { EC - 4C } \\
\text { EB - 4CPL arranjo } 1: 1: 1: 1\end{array}$ \\
\hline Zoea IV & $\begin{array}{l}\text { Boschi et al. (1967) } \\
\text { Presente trabalho }\end{array}$ & $\begin{array}{c}E C-5 C \\
\text { EB - C marginais e } 6 \mathrm{C} \text { submarginais } \\
E C-1 \mathrm{CL}, 9 \mathrm{CPL} \\
\mathrm{EB}-4 \mathrm{CL}, 11 \mathrm{CPL}\end{array}$ & $\begin{array}{c}E C-5 C P L \\
E X-17 \mathrm{~A} 19 \mathrm{C} \\
\text { EC - 5CL, 5CPL } \\
\text { EB - 9CPL, 7CL } \\
\text { EX-24 CPL marginais }\end{array}$ & $\begin{array}{c}\text { EN-2C em cada segmento } \\
3 S \cdot 1 \mathrm{CPL}\end{array}$ & $\begin{array}{c}- \\
\mathrm{EB}-4 \mathrm{CPL}\end{array}$ \\
\hline Megalopa & $\begin{array}{l}\text { Boschi et al. (1967) } \\
\text { Presente trabalho }\end{array}$ & $\begin{array}{c}\text { EN - unissegmentado com espinhos } \\
\text { EN - bissegmentado com } 6 \mathrm{CL}\end{array}$ & $\begin{array}{c}\text { EC, EB - ES nos bordos } \\
\text { EX - com cerdas nos bordos } \\
\text { LPC - } 1 \mathrm{CL}, 15 \mathrm{CPL} \\
\text { LDC }-5 \mathrm{CPL} \\
\text { LPB }-1 \mathrm{CPL}, 6 \mathrm{CL} \\
\text { LDB }-12 \mathrm{CL} \\
\text { EX }-48 \mathrm{CPL} \text { marginais }\end{array}$ & $\begin{array}{c}E X-4 C L \\
E N-1 \text { ou } 2 C \\
E B-1 C L, 14 C P L \\
E C-1 C P L, 14 C L \\
E X-6 C P L \\
E N-2 C L\end{array}$ & $\begin{array}{c}\text { PR - 12, 13CE } \\
\text { PR - 2CPL } \\
E N-1 C L, 14 C P L\end{array}$ \\
\hline
\end{tabular}

A) Bordo anterior (C) cerdas

FL) face lateral, (FM) face mesia

DB) lobo distal endito basal

BC) lobo proximal endito bas

M) margem, (MCT) microtriquia

(MPA) microtríquias da porção

terminal afilada, (SL) superficie lateral $2^{\circ}$ segmento do endopodito

N) endopodito, (ES) espinhos

(EX) exopodito .

(1S) $1^{\circ}$ segmento endopodito

(C) cerdas

inhosa 
Tabela V. Continuação.

\begin{tabular}{|c|c|c|c|c|c|}
\hline Estágios & Referência & $\begin{array}{l}\quad 3^{\circ} \text { Maxilipodo } \\
\text { (1S) } 1^{\circ} \text { segmeno endopodito } \\
\text { (2S) } 21^{\circ} \text { segmeno endopodito } \\
\text { (3S) } 3^{\circ} \text { segmeno endopodito } \\
\text { (4S) } 4^{\circ} \text { segmeno endopodito } \\
\text { (5S) } 5^{\circ} \text { segmeno endopodito } \\
\text { (C) cerdas, (CE) cerda espinhosa } \\
\text { (CL) cerda lisa, (CPL) cerda plumosa } \\
\text { (E) estetos, (EN) endopodito } \\
\text { (EPI) epipodito, (ES) espinhos } \\
\text { (EX) exopodito, (PD) porção distal } \\
\text { (PM) porção medial, (PP) porção proximal } \\
\text { (PR) protopodito }\end{array}$ & $\begin{array}{l}\text { (B) basi } \\
\text { (C) carpo } \\
\text { (C) cerdas } \\
\text { (CL) cerdápodos lisa } \\
\text { (CPL) cerda plumosa } \\
\text { (CX) coxo } \\
\text { (D) dátilo } \\
\text { (E) estetos } \\
\text { (ES) espinhos } \\
\text { (I) isquio } \\
\text { (M) mero } \\
\text { (P) própodo }\end{array}$ & $\begin{array}{l}\text { Pleópodos } \\
\text { (C) cerdas } \\
\text { (CL) cerda lisa } \\
\text { (CPL) cerda plumosa } \\
\text { (E) estetos } \\
\text { (ES) espinhos } \\
\text { (EX) exopodito }\end{array}$ & $\begin{array}{l}\quad \text { Urópodos } \\
\text { (C) cerdas } \\
\text { (CL) cerda lisa } \\
\text { (CPL) cerda plumosa } \\
\text { (E) estetos } \\
\text { (ES) espinhos }\end{array}$ \\
\hline \multirow[t]{2}{*}{ Zoea I } & Boschi et al. (1967) & - & - & - & - \\
\hline & Presente trabalho & - & - & - & - \\
\hline \multirow[t]{2}{*}{ Zoea II } & Boschi et al. (1967) & - & - & - & - \\
\hline & Presente trabalho & - & - & - & - \\
\hline \multirow[t]{2}{*}{ Zoea III } & Boschi et al. (1967) & - & - & - & - \\
\hline & Presente trabalho & - & - & - & - \\
\hline \multirow[t]{2}{*}{ Zoea IV } & Boschi et al. (1967) & - & - & - & - \\
\hline & Presente trabalho & - & - & - & - \\
\hline \multirow[t]{2}{*}{ Megalopa } & Boschi et al. (1967) & $\begin{array}{c}\text { PR - } 12,13 \mathrm{CE} \\
1 \mathrm{~S}-11 \mathrm{ES}, 2 \mathrm{~S}-4 \text { a } 6 \mathrm{ES}, 4 \mathrm{~S}-6 \text { a } 7 \mathrm{ES} \\
5 \mathrm{~S}-5 \text { a } 6 \mathrm{ES}, \mathrm{EX}-3 \mathrm{C} \text { terminais } \\
\text { EPI }-14 \text { a } 16 \mathrm{C}\end{array}$ & $D-C_{P-C}{ }^{3 C}$ & $17 \mathrm{C}, 17 \mathrm{C}, 15 \mathrm{C}, 15 \mathrm{C}$ & $8-9 C$ \\
\hline & Presente trabalho & $\begin{array}{c}\text { PR - 20CPL, PM EX - 3CL, PD EX - 4CPL } \\
\text { PP EDI - } 13 \text { CPL, PM EPI - } 16 C L \\
\text { PD EPI - 4CPL }\end{array}$ & $\begin{array}{c}D-10 D-8 D-6 D-6 D-5 \\
P-5 P-12 P-11 P-10 P-5 \\
C-5 C-8 C-10 C-8 C-4 \\
M-5 M-13 M-19 M-14 M-8 \\
1-3|-3|-3|-3|-4 \\
B-3 B-4 B-3 B-3 B-5 \\
C X-3 C X-5 C X-4 C X-5 C X-5\end{array}$ & $12 \mathrm{CPL}, 13 \mathrm{CPL}, 16 \mathrm{CPL}, 15 \mathrm{CPL}$ & $9 \mathrm{CPL}$ \\
\hline
\end{tabular}




\begin{tabular}{|c|c|c|c|}
\hline Estágios & Referência & $\begin{array}{l}\text { (1S) } 1^{\circ} \text { somito } \\
\text { (2S) } 2^{\circ} \text { somito } \\
\text { (3S) } 3^{\circ} \text { somito } \\
\text { (4S) } 4^{\circ} \text { somito } \\
\text { (5S) } 5^{\circ} \text { somito } \\
\text { (6S) } 6^{\circ} \text { somito } \\
\text { (C) cerdas } \\
\text { (CL) cerda lisa } \\
\text { (CPL) cerda plumosa } \\
\text { (E) estetos } \\
\text { (ES) espinhos } \\
\text { (P) par } \\
\text { (PEM) projeções espiniformes nas margens dos somitos } \\
\text { (PL) póstero laterais } \\
\text { (RPD) região póstero-dorsal dos somitos } \\
\text { (SD) superfície dorsal }\end{array}$ & $\begin{array}{l}\text { (C) cerdas } \\
\text { (CL) cerda lisa } \\
\text { (CPL) cerda plumosa } \\
\text { (E) estetos } \\
\text { (ES) espinhos } \\
\text { (ESP) espinhos plumosos } \\
\text { (ET) extremidade } \\
\text { (FT) fórmula do telso } \\
\text { (MILR) margem lateral de cada ramo da furca } \\
\text { (MPC) margem posterior convexa } \\
\text { (PL) processo longo do telso } \\
\text { (SB) forma subretangular } \\
\text { (SD) superficie dorsal }\end{array}$ \\
\hline Zoea I & $\begin{array}{l}\text { Boschi et al. (1967) } \\
\text { Presente trabalho }\end{array}$ & PEM - ES & $\begin{array}{l}P L-6 E S P \\
\text { MILR - } 35 \mathrm{CL}\end{array}$ \\
\hline Zoea II & $\begin{array}{l}\text { Boschi et al. (1967) } \\
\text { Presente trabalho }\end{array}$ & $\begin{array}{c}- \\
\mathrm{RDP}-1 \text { par } \mathrm{CL}\end{array}$ & $\begin{array}{c}\mathrm{FT}-3+3-\mathrm{CPL} \\
\mathrm{PL}-6 \mathrm{ESP} \\
\mathrm{MILR}-35 \mathrm{CL} \\
\mathrm{FT}-3+3 \mathrm{CPL} \\
\end{array}$ \\
\hline Zoea III & $\begin{array}{l}\text { Boschi et al. (1967) } \\
\text { Presente trabalho }\end{array}$ & $\begin{array}{c}\text { PEM - ES } \\
1 \mathrm{~S}-3 \mathrm{CL} \text {, dorsais }\end{array}$ & MILR - ${ }^{-} 40 \mathrm{CL}$ \\
\hline \multirow[t]{2}{*}{ Zoea IV } & Boschi et al. (1967) & $\begin{array}{l}2 \mathrm{~S}, 3 \mathrm{~S}, 4 \mathrm{~S}, 5 \mathrm{~S}-1 \text { par } \mathrm{CL} \\
1 \mathrm{~S}-2 \text { ou } 3 \mathrm{C} \text { dorsais }\end{array}$ & - \\
\hline & Presente trabalho & $2 S, 3 S, 4 S, 5 S-1$ par $C L$ & MILR - 40CL \\
\hline Megalopa & $\begin{array}{l}\text { Boschi et al. (1967) } \\
\text { Presente trabalho }\end{array}$ & $\begin{array}{c}1 \mathrm{~S} \text { a } 3 \overline{\mathrm{S}} \text { - PEM } \\
1 \mathrm{~S}-11 \mathrm{CPL} \text { - região mediana } \\
2 \mathrm{~S}, 3 \mathrm{~S}, 6 \mathrm{~S}-1 \text { par } \mathrm{CL} \text { póstero-laterais } \\
2 \mathrm{~S}-2 \mathrm{CL}-\mathrm{PL}, 3 \mathrm{P} \mathrm{CL}-\mathrm{SD} \\
4 \mathrm{~S}-5 \mathrm{P} \mathrm{CL} \mathrm{SD} \\
6 \mathrm{~S}-2 \mathrm{CL} \mathrm{PL}\end{array}$ & $S R, E \bar{T}-4 C P L$ \\
\hline
\end{tabular}

$2^{\circ}$ somit

cerda plumos

(P) par

(PL) póstero laterais

RPD) região postero-dorsal dos somitos 
comparada à megalopa descrita por BoscHI et al. (1967) apresenta vários padrões corporais, sendo o descrito por BOSCHI et al. (1967) considerado como normal e os demais anômalos. Tal situação permite inferir uma possível resposta à presença destas estruturas atípicas da fase de megalopa, considerando-as típicas da fase de zoea, como evidenciado pela presença do espinho rostral, espinho lateral, espinho dorsal e o telso em forma de furca (Fig. 20). A presença de tais caracteres morfológicos na fase de megalopa seria induzida pela situação artificial de laboratório, uma vez que até o presente momento não foi encontrada nenhuma citação a respeito deste processo.

Dentre os aspectos abordados na literatura, no que se refere ao desenvolvimento pós-embrionário, muitos são discutidos sob os pontos de vista da variação no número de estágios larvais, estruturas que caracterizam cada uma das fases larvais (PoRTER 1960, Costlow 1963, 1965; WeAR 1967; Williamson 1982; ANGER et al. 1995). Para CostLow (1965), na seqüência normal do desenvolvimento das zoeas, a variabilidade nos estágios larvais ou pequenas diferenças nos caracteres morfológicos das larvas podem também estar ligadas a um mal funcionamento do sistema endócrino, de maneira a não permitir o desenvolvimento dos caracteres morfológicos dentro dos padrões geralmente aceitos como normais em sincronização com a freqüência de mudas, que é controlada por um sistema endócrino separado. Sob este duplo sistema de controle, deficiência dietética ou a ausência de traços de certos elementos orgânicos ou inorgânicos na água do mar podem impedir ou atrasar o funcionamento normal dos mecanismos endócrinos que controlam o desenvolvimento. Externamente, estas deficiências, bem como o consequente mal funcionamento do sistema endócrino, podem se manifestar como uma variabilidade no número de estágios larvais ou em pequenas diferenças nos caracteres morfológicos das larvas.

Devido ao pequeno número de espécies analisadas, torna-se difícil diagnosticar as prováveis causas das variabilidades morfológicas na fase de megalopa de Chasmagnathus granulata, todavia, como as alterações morfológicas apareceram com maior intensidade em somente um único cultivo oriundo de uma única fêmea ovígera as causas de natureza endócrina apontadas por CosTLOW (1963, 1965), parecem ser as mais prováveis visto que foram realizados mais quatro cultivos nas mesmas condições com quatro fêmeas ovígeras diferentes e não foram mais obtidas estas variações no plano morfológico desta espécie.

AGRADECIMENTOS. Os autores agradecem à FAPERGS pelo incentivo através de Bolsa de Iniciação Científica: processo n 95510175 . Ao MSc. Rony R.R. Vieira e MSc. Roberta Barutot pelas sugestões.

\section{REFERÊNCIAS BIBLIOGRÁFICAS}

AIKAWA, H. 1937. Further notes on Brachyuran larvae. Rec. Oceanogr. Works Japan 9; 87-162.

ANGer, K.; D. SChreiben \& M. Montú. 1995. Abreviated larval development of Sesarma curacaoense (Rathbun, 1897) (Decapoda: Grapsidae) reared in the laboratory. Nauplius 3: 127-154.

Bookнout, C.G. \& J.D. Costlow JR. 1974. Larval development of Portunus spinicarpus reared in the laboratory. Bull. Mar. Sci. 24: 20-51.

Revta bras. Zool. 18 (4): 1281 - 1317, 2001 
Boschi, E.E.; M.A. Scelzo \& B. Goldstein. 1967. Desarrollo larval de dos especies de crustáceos decápodos en el laboratorio. Pachycheles haigae Rodrigues da Costa (porcellanidae) y Chasmagnathus granulata Dana (Grapsidae). Bol. Inst. Biol. Mar. 12: 4-46.

Brossi-Garcia, A.L. \& M.D. Rodrigues. 1993. Zoeal Morphology of Pachygrapsus gracilis (Saussure, 1858) Decapoda, Grapsidae reared in the laboratory. Invert. Reprod. Dev. 24 (3): 197-204.

CALAZANS, D. \& R. INGLE. 1998. The setal inorphology of the larval phase of the argentinean red shrimp Pleoticus muelleri Bate, 1888 (Decapoda: Solenoceridae). Invert. Reprod. Dev. 33 (2-3): 109-126.

Carbonnier, P. 1869. L'Ecrivise, Moeurs, Reproduction Education. Paris, Libr. Sci. Industri. Agric.

CRISTIANSEN, M.E. 1973. The complete larval development of Hyas arenaeus (Linnaeus) and Hyas coarctatus Leach (Decapoda, Brachyura, Majidae) reared in the laboratory. Norw. Jour. Zool. 21 (3): 63-89.

COstlow JR., J.D. 1963. Larval development. AIBS Bull. 13 (5): 63-65.

1965. Varability in larval stages of the blue crab Callinectes sapidus. Bio. Bull. 128 (1): 58-66.

Costlow JR., J.D. \& C.G. Bookhout. 1959. The larval development of Callinectes sapidus Rathbun reared in the laboratory. Biol. Bull. 116 (3): 373-396.

FACTOR, J.R. 1978. Morphology of the mouthparts of larval lobsters Homarus americanus (Decapoda: Nephropidae), with special emphasis on their setae. Biol. Bull. 154: 383-408.

FARMER, A.S. 1974. The funcional morphology of the mouthparts and pereiopods of Nephrops norvegicus (L.) (Decapoda: Nephropidae). Jour. Nat. Hist. 8: 121-142.

Ferris, G. F. 1934. Setae. Can. Ent. 66: 145-150.

FISH, S. 1972. The setae of Eurydice pulchra (Crustacea: Isopoda). Jour. Zool., London 166: 163-177.

Fransozo, A. 1987. Desenvolvimento larval de Eriphia gonagra (Fabricius, 1781) (Decapoda, Xanthidae), em laboratório. Revta bras. Zool. 4 (3): 165-179.

Fransozo, A. \& N.J. Hebling. 1986. Desenvolvimento larval de Sesarma (Holometopus) rectum Randall, 1840 (Decapoda, Grapsidae) em laboratório. Rev. Brasil. Biol. 46 (2): 353-364.

Hale, H. M. 1931. The post-embrionic development of an Australian xanthid crab (Pilumnus vestitus Haswell). Rec. S. Aust. Mus. 4 (3): 321-31

Hebling, N.J. \& A. Fransozo. 1982. Desenvolvimento pós-embrionário de Paguristes erythrops Holthuis, 1959 (Decapoda, Diogenidae) em laboratório. Rev. Brasil. Biol. 42 (1): 117-128.

HuXLEY, T.H. 1880. The crayfish: na introduction to the study of zoology. london: Kegan Paul \& Co.

Hyman, O.W. 1924. Studies on larvae of crabs of the family Grapsidae. Proc. U.S. Nat. Mus. 65 (10): $1-8$.

- 1925. Studies on the larvae of crabs of the family Xanthidae. Proc. U.S. Nat. Mus.67 (3): $1-36$.

INGLE, R. 1992. Larval Stages of Northeastern Atlantic crabs. An Ilustrated Key. London, Chapman \& Hall, $363 p$.

JACQUES, F. 1989. The setal system of crustaceans: Types of setae, groupings, and funcional morphology, p.1-13. In: F.R. Schram (Ed.). Functional Morphology and Grooming in Crustacea. A.A. Balkema, 225p.

LAVALLI, K.L. \& J.R. FACTOR. 1992. Functional morphology of the mouthparts of juvenile lobsters Homarus americanus (Decapoda: Nephropidae), and comparison with the larval stages. Jour. Crust. Biol. 12 (3): 467-510.

- 1995. The Feeding Apendages, p. 349-393. In: J. R. FACTOR (Ed.) Biology of the Lobster Homarus americanus. New York, Academic Press Inc.

Lebour, M.V. 1928. The larval stages of the plymouth Brachyura. Proc. Zool. Soc. London: 473-560.

Longmuir, E. 1983. Setal development, moult-staging and ecdysis in the banana prawn Penaeus merguiensis. Mar. Biol. 77: 183-190.

NARCHI, W. 1973. Crustáceos: Estudos Práticos. São Paulo, Edusp, 116p.

Panning, A. 1924. Das statocyste von Astacus fluviatilis (Potamobius astacus Leach) und ihre Beziehungen zu dem sie ungenbended Gewebe. Z. wiss. Zool. 123: 305-358. 
Pohle, G. \& M. TElford. 1981. Morphology and classification of decapod crustacean larval setae: a scanning electron microscrope study of Dissodactylus crinitichelis Moreira, 1901 (Brachyura: Pinnotheridae). Bull. Mar. Sci. 31: 736-752.

PorTer, H.J. 1960. Zoeal stages of the stone crab, Menippe mercenaria Say. Chesapeake Sci. 1 (3-4): 168-177.

Rieger, P.J. \& N.J. Hebling. 1993: Desenvolvimento larval de Hepatus pudibundus (Herbst, 1785) (Decapoda, Calappidae) em laboratório. Rev. Brasil. Biol. 53 (4): 513-528.

RIEGER, P.J. \& R.R.R. VIEIRA. 1997: Desenvolvimento larval de Cyrtograpsus angulatus Dana 1851 (Crustacea, Decapoda, Grapsidae), em laboratório. Revta bras. Zool. 14 (3): 601-623.

Ringel, M. 1924. Zur Morphologie des Verderdarmed (Schulund und Magen) von Astacus fluviatilis (Potamobius astacus). L. Z. wiss. Zool. 123: 498-554.

Rodrigues, M.D. \& N.J. Hebling. 1989. Ucides cordatus cordatus (Linnaeus, 1763) (Crustacea, Decapoda). Complete larval development under laboratory conditions and its systematic position. Revta bras. Zool. 6 (1): 147-166.

RodRigues, S.A. 1976, Sobre a reprodução, embriologia e desenvolvimento larval de Callichirus major Say, 1818 (Crustacea, Decapoda, Thalassinidae). Bol. Zool., São Paulo, 1: 85-104.

Thomas, W.J. 1970. The setae of Austropotamobius pallipes (Crustacea: Astacidae). Jour. Zool., London, 160: 91-142.

van Herp, F. \& C. Bellon-Humbert. 1978. Setal development and molt prediction in the larvae and adult of the crayfish Astacus Leptodactylus (Nordmann, 1842). Aquaculture 14: 289-301.

WATLing, L. 1989. A classification system for crustacean setae based on the homology concept. p. 15-26 In: F. R. Schram (Ed.). Functional morphology of feeding and grooming in crustacea. Crustacean Issues, VI+225p.

Wear, R. G. 1967. Life-history studies on New Zealand Brachyura. I - Embrionic and post-embrionic development of Pilumnus novaezealandiae Filhol, 1886, and of Pilumnus lumpinus Bennett, 1964 (Xanthidae, Pilumnidae). New Zealand Jour. Mar. Freshwat. Res. 1:482-535.

Williamson, D.I. 1982. Larval morphology and diversity. In: D.E. Bliss (Ed.). The Biology of Crustacea. Embriology, Morphology and Genetics. New York, Academic Press, Vol. 2, 440p.

Recebido em 21.IX.2000; aceito em 01.XI.2001. 